Optimal Inventory Policy Through Dual Sourcing

by

Volodymyr Miklyukh

A thesis submitted in conformity with the requirements

for the degree of Master of Applied Science Graduate Department of Chemical Engineering

University of Toronto

(C) Copyright 2017 by Volodymyr Miklyukh 


\title{
Optimal Inventory Policy Through Dual Sourcing
}

\author{
Volodymyr Miklyukh \\ Master of Applied Science \\ Graduate Department of Chemical Engineering \\ University of Toronto
}

2017

\begin{abstract}
We consider a risk-averse firm that utilizes dual-sourcing for perishable or seasonal goods with uncertain customer demand. Using real options theories, we provide two models aimed at determining optimal order quantities to maximize the firm's expected profit. Furthermore, we can consider the demand to be an observable process correlated to a traded, which can be hedged to reduce profit uncertainty. A single offshore single local order period (SOSLOP) model provides a pseudo-analytical solution which can be easily solved to determine an optimal offshore and local order quantities based on the manufacturers' lead times, and a more realistic single offshore multiple local order period (SOMLOP) model uses numerical methods to determine optimal order quantities. Finally, a method for matching distributions of expected demands based on managerial estimates can be applied to any of the aforementioned models and be easily incorporated into the industry.
\end{abstract}




\section{Contents}

$\begin{array}{ll}\text { Contents } & \text { iii }\end{array}$

List of Tables $\quad$ iv

$\begin{array}{ll}\text { List of Figures } & \text { v }\end{array}$

\begin{tabular}{lll}
\hline 1 & Introduction & 1
\end{tabular}

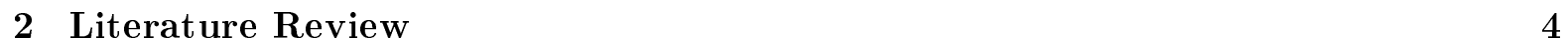

2.1 Inventory Control . . . . . . . . . . . . . . . . . . . 4

2.2 Operational and Financial Hedging . . . . . . . . . . . . . . . . . . . . . 6

2.3 Disruptions to System . . . . . . . . . . . . . . . . . . . . 8

2.4 Game Theory Approaches . . . . . . . . . . . . . . . . . . . . . 9

$\begin{array}{llr}3 & \text { Model Formulation } & \mathbf{1 0}\end{array}$

$3.1 \quad$ Single Offshore Single Local Order Period (SOSLOP) Model . . . . . . . . . . . . 11

3.2 Single Offshore Multiple Local Order Period (SOMLOP) Model . . . . . . . . . . 18

$3.3 \quad$ Incorporation of the Matching Method $\ldots \ldots \ldots \ldots \ldots \ldots$. . . . . . . . 21

\begin{tabular}{lll}
\hline & Results & 25
\end{tabular}

4.1 Optimal Local Order Quantity . . . . . . . . . . . . . . . . . . . 26

4.2 Performance of SOSLOP Model $\ldots \ldots \ldots \ldots$. . . . . . . . . . . . . . 27

4.3 Performance of SOMLOP Model ～. . . . . . . . . . . . . . . . . . . . . . . . 31

4.3.1 Observation of SOMLOP Model with Three Local Order Periods . . . . . 31

4.3 .2 Local Order Quantities . . . . . . . . . . . . . . . . . . . . . 32

4.4 The Value of Multiple Local Order Quantities . . . . . . . . . . . . . . . . . . . 34

$4.4 .1 \quad$ Effect of Local Product Purchasing Cost $C_{U} \ldots \ldots \ldots$. . . . . . . . . 35

4.4 .2 Minimum Order Quantities . . . . . . . . . . . . . . . . . . 37

\begin{tabular}{|lll}
5 & Conclusion and Future Work & 39
\end{tabular}

\begin{tabular}{ll}
\hline Bibliography & 40
\end{tabular} 


\section{List of Tables}

$3.1 \quad$ Expected Monthly Managerial Estimates $\left(V_{k}\right) \ldots \ldots \ldots \ldots$. . . . . . . 22

$4.1 \quad$ Optimal local order quantity $U^{*}$ with changing offshore order quantities $M$. . . 26 


\section{List of Figures}

1.1 Effect of Drift on Future Expected Demand $\ldots \ldots \ldots \ldots$

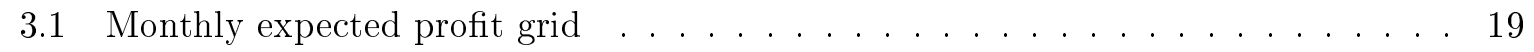

3.2 Expected profit calculation process, based on previous month's inventory level and expected demand $\ldots \ldots \ldots \ldots$. . . . . . . . . . . . . 20

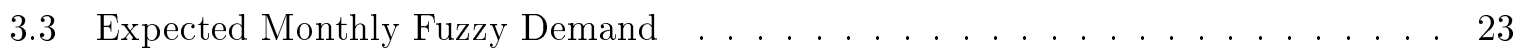

3.4 Histogram of Underlying Stochastic Process Matched with Managerial Estimates; $\mu=0.2, \sigma=0.3, X_{0}=100, T=6 / 12 \ldots \ldots \ldots \ldots 24 \ldots \ldots \ldots$

4.1 Simulated optimal local order quantity $U^{*}$ with changing offshore order quantities $M P=10, P_{\text {Salv }}=3, P_{\text {Strat }}=4, C_{U}=6, C_{M}=4, \tau=6 / 12, X_{0}=40 \ldots$. . . . 26

4.2 Expected profit contours based on underlying distribution type: Normal (Standard Brownian Motion) vs Lognormal (Geometric Brownian Motion) $P=$

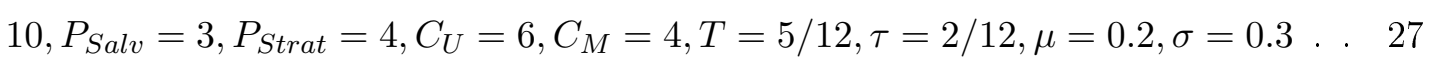

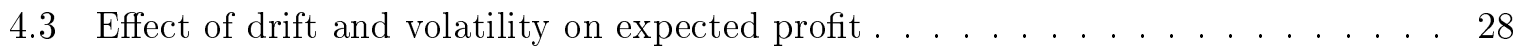

4.4 Optimal Offshore and Local Order Quantities; $\mu=0.2, \sigma=0.3, T=\frac{9}{12}, \tau=\frac{5}{12}$, $C_{U}=6, C_{M}=5, P=10, P_{\text {Strat }}=4, P_{\text {Salv }}=3 \ldots \ldots \ldots \ldots \ldots$

4.5 Expected profit contour . . . . . . . . . . . . . . . . . . 29

4.6 Maximum expected profit; $C_{U}=5, \tau=0: \frac{5}{12}, T=\frac{5}{12}: 1 \ldots \ldots$. . . . . 30

4.7 Expected Profit with Multiple Local Orders; $\mu=0.2, \sigma=0.3, T=\frac{9}{12}, T_{n-5}:$ $T_{n-3}=\frac{5}{12}: \frac{7}{12}, C_{U}=6, C_{M}=5, P=10, P_{\text {Strat }}=4, P_{\text {Salv }}=3 \ldots \ldots . . .31$

4.8 Local Purchase Quantities; $t=T_{n-3} \ldots \ldots \ldots \ldots \ldots \ldots$

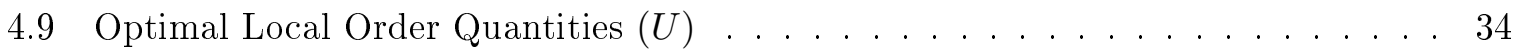

4.10 Offshore Order Quantities; $t=0$. . . . . . . . . . . . . . . . 34

4.11 Offshore Purchase Quantities and Profit - No Local Orders; $t=0$. . . . . . . . . 35

4.12 Expected Profit with Varying $C_{U}$ : No Local Order Periods; $\mu=0.2, \sigma=0.3$, $T=\frac{9}{12}, C_{U}=5: 10, C_{M}=5, P=10, P_{\text {Strat }}=4, P_{\text {Salv }}=3 \ldots \ldots$. . . . . 36

4.13 Expected Profit with Varying $C_{U}: 3$ Local Order Periods; $\mu=0.2, \sigma=0.3$, $T=\frac{9}{12}, T_{n-5}: T_{n-3}=\frac{5}{12}: \frac{7}{12}, C_{U}=1: 10, C_{M}=5, P=10, P_{\text {Strat }}=4, P_{\text {Salv }}=336$

4.14 Expected Profit Under Minimum Offshore and Local Order Quantities . . . . . . 37

4.15 Optimal Order Quantities Under Minimum Order Policy . . . . . . . . . . . . . . 38 


\section{Chapter 1}

\section{Introduction}

To maximize profit in the manufacturing sector, and many other sectors, businesses turn to offshore production because of the low manufacturing costs. However, due to uncertain consumer demand and long lead times, it is difficult to determine an optimal offshoring strategy for riskaverse firms. To effectively hedge the risk associated with offshoring, a dual-sourcing model is proposed. The dual-sourcing model will enable companies to maximize their profit while eliminating risk by applying a real options approach to decision making. Real options valuation techniques, developed largely by [Trigeorgis, 1996] and [Dixit and Pindyck, 1994], give the firm the right - but not the obligation - to undertake projects or initiatives. As a result, project managers have a direct influence on the value of the option, and in the presented case - the product order quantities from each (local and offshore) supplier.

Consider the production and sale of winter boots. As a seasonal item, winter boots experience high demand during the winter months. However, in the summer months, it is difficult for retailers to accurately determine the expected future demand of winter boots due to the unknown weather. Figure 1.1 represents the distributions of demand at future months when observing them from time $t=0$ and the red line represents the mean expected future demand of winter boots. 


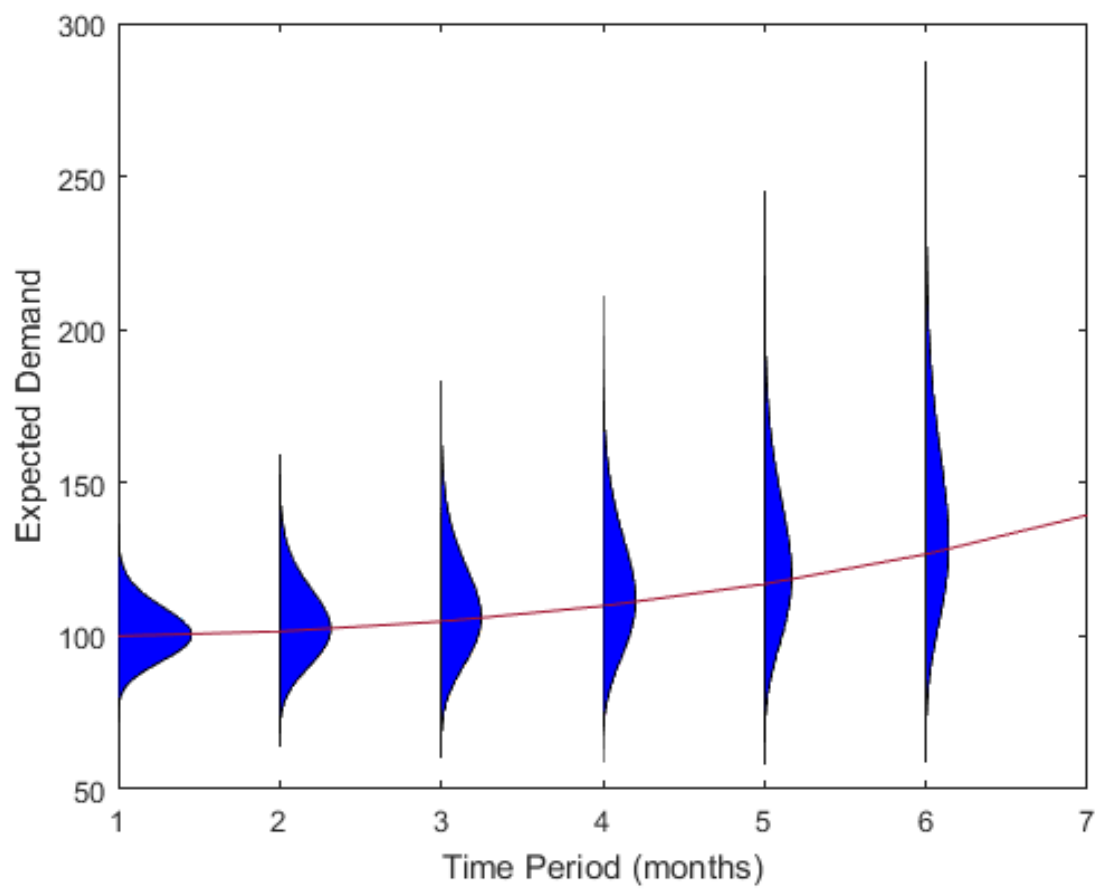

Figure 1.1: Effect of Drift on Future Expected Demand

When observing the expected demand at month 1 , the operation managers can approximate, with relative confidence, the demand that month. However, when observing the expected demand 6 months out, the diffusion of expected demand increases with time and although it is clear that the expected demand trends upwards, it is very difficult to determine the future demand with reasonable accuracy. This is the reality faced for the case of ordering an optimal quantity of winter boots which meets consumer demand, months in the future. Additionally, the firm can face losses in profit when there is excess inventory at the end of the selling period. As a seasonal product, it is impractical for the firm to store winter boots until the subsequent winter season, and any excess inventory at the end of the season has to be salvaged at a reduced price. Finally, if consumer demand exceeds expectations and the firm has an inventory shortage, competitors are able to capture consumer demand and the firm does not maximize on their potential profits.

This paper offers an innovative solution to a dual-sourcing perishable inventory optimization model with managerial flexibility. Under the condition that the firm chooses to order from each source (offshore and local) only one time, a pseudo-analytical equation is offered. Whereas, under a more practical scenario, where the firm orders once from the offshore source and has the option to place multiple orders from their local supplier, numerical methods have to be used for proper valuation. Both of these models have the ability to fully incorporate managerial estimates through the Matching Method developed by [Jaimungal and Lawryshyn, 2016]. Under the Matching Method, the modeled expected demand can be directly translated in accordance to 
industry experts' estimates on low, medium, and high expected demands - effectively matching a distribution of estimated demands.

In the next sections a literature review of various inventory optimization methods will be present, followed by the introduction and derivation of a single offshore single local order period (SOSLOP) pseudo-analytical model and a more realistic, single offshore multiple local order period (SOMLOP) model. The performance of both models will be analyzed with respect to changing parameters, and results for minimum required order quantities will be shown. Finally, the aforementioned Matching Method will be applied to the dual-sourcing case to demonstrate how managerial inputs, along with underlying stochastic drivers, can help with decision making in the firm. 


\section{Chapter 2}

\section{Literature Review}

This review is structured in sections which compare existing literature to our proposed models. Initially, an analysis of current and historical profit maximization and inventory control techniques will be reviewed. Afterwards, research will be presented which bypasses optimal inventory control, and instead focuses on operational and financial hedging practices to ensure constant profits, and brief review of game theory approaches to determining supply capacity will be discussed. Finally, disruptions that greatly affect expected profit, such as supplier reliability and product delivery will be discussed, before concluding.

\subsection{Inventory Control}

Profit maximization in the retail industry for perishable products can be achieved through an optimal inventory policy. If a retail firm controls their inventory level such that consumer demand is perfectly met, the firm maximizes their profit for the period. By capturing the full customer demand and leaving no excess inventory at the end of the period, the firm rejects competitors from entering the market and prevents potential losses in excess inventory disposal. Dual-source operational hedging is a concept long studied by academics and industry. Early research from [Barankin, 1961] treated the local supplier as an emergency supplier that provided needed service during times of peak demand when standard inventory management did not suffice. For the case when the lead-time difference between the two suppliers was exactly one period, Fukuda, 1964 determined that the optimal order policy is a dual-index policy. The dualindex policy involves constant replenishment from an offshore source, utilizing the nearshore supplier only when inventory falls below a target level. [Allon and Mieghem, 2010] utilize a simple "square root" formula which compares the trade-off between the holding cost of safety stock to sourcing cost savings to create a sourcing policy between the offshore and nearshore suppliers for high-volume systems. A much more complex problem of when the lead time differences are more than one period between the suppliers, the optimal policy becomes difficult to compute and has a complex structure [Whittemore and Saunders, 1977]. The issue of various multiple sourcing models is reviewed in depth by Minner, 2003. The models presented in 
this research treat the local supplier similarly; demand that is not matched through the offshore order quantity will be ordered from the local supplier. A means of determining optimal inventory levels for a perishable product with fixed costs and uncertain demand was developed by Arrow et al., 1951], known today as the newsvendor model and was used in conjunction with the aforementioned local supplier assumptions to determine optimal supplier order quantities.

The newsvendor model has been expanded on extensively from its original form to incorporate many parameters and timelines. Agrawal and Seshadri, 2000 provide a single period newsvendor inventory model where the selling price of a product affects the expected demand. With the application of a scaling parameter to the mean and standard deviation of the expected demand based on the product's selling price, the authors were able to construct a model used to maximize the profit function through a Poisson process. A more specific case where the expected demand for a seasonal product is highly sensitive to weather is observed by [Fu et al. 2014]. Assuming that the weather can be either "high" or "low", the product prices change accordingly and the retailer has to make decisions at the beginning of the period on the order quantity and seasonal retail prices. The authors determine that there exists a profit function, continuous and concave in nature, which provides the optimal solution to product order quantity and price. Using an iterative solution algorithm, Rabbani et al., 2016 were able to determine optimal dynamic pricing methods and replenishment policies for products with both deteriorating quality and physical quantity. The authors were able to do this by setting the selling price of products as a time-dependent function of initial (non-deteriorated) price and discount rate, and the consumer demand as a function of the change in selling price and quality of inventory. Their findings conclude that quality deterioration has a significant effect on the demand rate, and therefore, expected profit; deteriorating inventory quantity does not have an effect on the expected demand rate but lowers the profit by effectively decreasing inventory and requiring product salvage. The argument that a firm can improve their profitability by targeting multiple markets with cyclical selling seasons is challenged by [He et al., 2010]. Assuming a variable demand for each market with a constant demand rate per specific market, the authors develop a production-inventory model for deteriorating products under this multi-market system. Considering a piecewise-constant demand function, they provide a solution procedure to determine the optimal replenishment schedule for raw materials based on a continuous production plan for finished products. A two-period model with a single supplier and price-sensitive consumer demand was analyzed by [Jia and Hub, 2011]. Similar to the approach taken by [He et al., 2010], the authors assume a variable wholesale price from the supplier that is constant throughout the period. With these assumptions, they show that for a two-period lifetime product, the optimal policies are identical at each period thus the optimal pricing strategy for perishable goods is only dependent on the inventory level at the beginning of each period. A method for adapting an inventory capacity strategy to the semiconductor industry was studied by [Chou et al., 2007. Using geometric Brownian motion (GBM) to calibrate uncertain demand, they compared two capacity strategies - reactive and conservative. The reactive strategy represents a now-or-never 
decision for each period while the conservative strategy considers all possible demand realizations over the semiconductor lifetime by using binomial demand trees in a newsvendor setting.

The models presented in our research utilize the newsvendor principles in determining optimal inventory levels; but where other researchers assume a correlation for future demand ([Agrawal and Seshadri, 2000], [Fu et al., 2014], Rabbani et al., 2016], [Jia and Hub, 2011]), we propose that demand be modeled as a stochastic process independent of external control similar to Chou et al., 2007]. This approach is more practical and the uniqueness in flexiblity of design and adjustment to industry needs, allow demand to be correlated with a dependent variable if necessary. Additionally, for the derivation of the models, the selling price of the product was assumed to be a constant variable. Similar to the research, for the presented models in this paper, fluctuations in selling price can be adjusted on a period-by-period basis, but must remain constant throughout the period.

\subsection{Operational and Financial Hedging}

Several authors have also applied conditional value-at-risk (CVaR) performance measures developed by |Uryasev and Rockafellar, 2000| to the newsvendor model. The CVaR criterion represents the trade-off between the expected profit and a certain risk measure, presenting the likelihood (at a specific confidence level) that a specific loss will exceed the value at risk. Cheng et al. 2009] investigate optimal pricing and ordering decisions under the CVaR criterion for both additive and multiplicative demand models for a single product. Meanwhile, Gotoh and Takano, 2007] consider risk minimization using CVaR in the newsvendor model based on the number of products and constraints considered. When a single product with no constraints is considered, a closed form solution is possible; however when multiple products with many constraints are used, the authors mention that a numerical solution is not possible to achieve, and the problem has to be reformatted into linear programs. While our research does not consider CVaR criterion, it can be easily implemented into the SOMLOP model and unnecessary to consider when implementing the Matching Method as the Matching Method uses managerial estimates as another risk-mitigating technique.

Instead of creating an optimal inventory re-ordering policy, various researchers attempted to offset the operational risk through financial hedging. Uncertainty, not only in product supply, but also in consumer demand was researched by [Okyay et al., 2014]. Their approach attempts to mitigate the negative product supply and consumer demand factors by investing in a portfolio of financial assets - stating that there is a correlation between the uncertainty in the inventory model and the financial market. By considering random supply and demand on the operations side and random prices on the financial market, the authors conclude that portfolios consisting solely of future contracts or futures and call options on the asset are the most effective hedging procedures. Yet a portfolio consisting of only call options has limited effectiveness. Under both presented cases, the authors determine that financial hedging is strongly dependent on the 
degree of correlation between the financial market and the firm's inventory policy. Expanding laterally, Kouvelis et al., 2014] study the management of commodity risks with respect to price and consumer demand in a multi-period model for a risk-averse firm that has the ability to buy from a long-term supplier at a fixed price and the spot market, or emergency supplier, at a random (spot) price. Alongside, the firm also has the option to financially hedge their decisions through financial contracts. Examining multiple financial hedging strategies and dynamically maximizing the mean-variance utility functions, the authors determine that the optimal hedging policy is never myopic and may lead to inventory reduction in the multi-period case, contrary to Gaur and Seshadri, 2005]. A method of incorporating foreign currency exposures among multicountry firms along with demand uncertainties was developed by [Li and Wang, 2010]. Much like the research presented here, the authors show that firms may benefit from sourcing with both local and offshore suppliers even if dual-sourcing exhibits slight negative contribution to profit. They go on to show that risk-averse firms are more intended to utilize local suppliers over offshore ones and keep more total capacity than risk-neutral firms. Using these findings, Chen et al. 2014] expanded on this work greatly and derived first-order conditions for the optimal utilities, capacities, and financial hedging sizes. By doing so, they showed that in the case of perfect correlation between exchange rates and demands, the risk-averse and risk-neutral optimal capacities and utilities are identical. The research expands to show the differences in financial and operational hedging. Extending contracts with multiple suppliers in low-cost countries, operational hedging provides the firm a competitive edge by reducing production costs; whereas financial hedging allows the firm to reduce the adverse effects with fluctuations in their expected profit.

It is known that for highly liquid risk-neutral firms, investors can create their own risk profile through portfolio replication and therefore the firm is indifferent to the idea of financial hedging. For risk-averse firms, research shows that the expected utility-maximizing inventory level is less than the expected value-maximizing inventory level due to concerns that future expected demand is not met and inventory must be salvaged or discarded at a loss ([Agrawal and Seshadri, 2000] and [Chen et al., 2001]). [Gaur and Seshadri, 2005] argues that hedging inventory levels is beneficial for both risk-neutral and risk averse firms, as hedging does not require additional financial investment and can be beneficial for some risk-neutral companies. Small privately-owned retailers would benefit from hedging inventory as it opens up capital to invest in other ventures.

The CVaR performance measure has also been applied to financial hedging techniques of operational risk. [Zhao and Huchzermeier, 2017] approach operational and financial decisions separately and consider a multinational corporation that utilizes capacity reshoring, production switching, and financial hedging to balance supply-demand mismatches and cash flow risk by optimizing the CVaR under aforementioned criteria. Their findings show that operational flexibility and financial hedging can complement each other and are substitutes in risk reduction. Operational flexibility enhances the firm's expected profit and reduces downside risk, whereas 
financial hedging minimizes this downside risk and expands the set of capacity decisions. As a result, proper coordination of operational and financial operations is crucial for the firm as financial hedging is able to negate the cash flow disruptions caused by operational flexibility. Alongside, [Park et al., 2017] show that production hedging can greatly reduce risk from value-at-risk (VaR) and CVaR perspectives while increasing expected profit. Their work takes an approach similar to [Zhao and Huchzermeier, 2017] by examining the interactions between financial and production hedging. The authors declare that financial hedging cannot take the place of production hedging in terms of an optimal solution for every given case; it works best as a complement to production hedging. In terms of risk aversion from exchange rate fluctuations, the optimal pricing decision is not one directional and attempting to hedge strictly through financial means can lead to both an increase and a decrease in price, as exchange rates fluctuate. This research tends to be consistent with the observations of [Chod et al., 2010], who agree that product flexibility and financial hedging complement each other when product demands are positively correlated. Product flexibility increases the value of financial hedging and vice-versa, financial hedging increases the value of product flexibility. By their reasoning, the opposite is also true and for negatively correlated product demand, product flexibility and financial hedging tend to decrease each other's value. As shown in the previous research, maximizing expected profit under the conditions presented in this research is unfeasible with solely financial hedging. As a result, financial hedging techniques will not be covered in the models presented in this research, and will be considered as future work to be coupled with the presented operational methods.

\subsection{Disruptions to System}

Supplier reliability, whether it be timely product delivery or order fulfillment, can greatly affect optimal inventory policy. The development of a single period, single product sourcing decision under demand uncertainty and variable supplier reliabilities was studied by [Burke et al., 2007. Incorporating into their model a diversification benefit function based on the number of suppliers, allowed their firm to modify their level of risk. Their findings show that there is a possibility of decline in diversification benefits as the number of suppliers grow, as maintaining a large supplier base posed excessive costs. When there is uncertainty about the major supplier's disruption, a capacity reservation contract between a buyer and a backup supplier is proposed by Hou et al. 2017]. Their study observes the ability for the buyer to choose whether to order from their contingent source, and goes on to set constraints that require the buyer to have a minimum order quantity from their emergency supplier. Using pre-determined wholesale prices, the authors derive optimal reservation quantities and contingent sourcing decisions for the buying firm and the backup supplier's optimal unit reservation price. [Parlar and Perry, 1996] considered a model where disruptions in product supply are prevalent and developed average cost models for single and multiple suppliers under constant demand, utilizing a Markov chain process for the 
case of two suppliers. Analytical closed-form solutions for single period dual-sourcing inventory control with supply disruptions for both channels were found by Xanthopoulos et al., 2011. Assuming a stochastic supply (yield) with a known demand, in special cases such as agricultural production, [Keren, 2009] considers additive and multiplicative yield risks within a single-period demand. Assuming an unlimited supply capacity with unreliable yield, [Shu et al., 2015] shows that the value of the optimized expected utility becomes less sensitive to the initial inventory level as the degree of risk aversion decreases. Very detailed reviews of various supply chain risks and their management styles have been done by [Tang, 2006] and [Ho et al., 2015]. Our models do not consider disruptions on the supplier-end. We assume that any orders placed through either supplier are delivered in full, and on a timely manner as determined by their specified lead times. The models presented in this paper were designed for ease-of-use in the industry, and incorporating supplier disruptions makes them overly complex and much more difficult to understand. The SOSLOP model will no longer be pseudo-analytical as it will be conditioned on order quantity and time along with uncertain demand, and the SOMLOP will have even more nested conditioning. As a result, supplier disruptions have been eliminated from this research and will be considered in future work.

\subsection{Game Theory Approaches}

Game theory approaches have also been applied to similar works. When a firm has partially observed supply-capacity information with stochastic consumer demand, WWang et al., 2010] considers a multiperiod problem where the current period's capacity observations influence the capacity distribution and value function for the next period. With the possibility that supply capacity can change between periods, the model behaves as a Markovian process and an optimal ordering policy is proposed. [Spinler and Huchzermeier, 2006] develop a framework between a buyer and seller of perishable goods or dated services, where the buyer future demand and seller future marginal costs and spot prices are uncertain. Treating the framework as a two period Stackelberg model, where the leader firm makes the first move and then the follower firm moves sequentially, they were able to derive analytical expressions for the buyer's optimal reservation quantity and the seller's optimal options tariff - creating risk-sharing benefits of options contracts to both the buyer and seller. The models presented in our research incorporate game theory logic with respect to meeting consumer demand. Where the previous research has applied game theory to determining expected demand, our approach utilizes a lost-profit function that comes into effect when consumer demand cannot be met and competitors are able to capture those extra customers. 


\section{Chapter 3}

\section{Model Formulation}

In this chapter we consider a firm which plans to order a seasonal or perishable product which indicates a distinct lifetime of the product from two possible sources to satisfy future uncertain domestic market demand. The two possible sources considered are a local manufacturer and an offshore manufacturer, each of which can operate independently from the firm as a contractor, or be a subsidiary to the firm.

When deciding on the order quantities from each supplier, the firm has to consider not only the product costs charged by each manufacturer, but also their respective production lead times. The local source typically offers faster delivery in terms of shorter lead times, but charges a premium in production costs. The advantage of the offshore source for the purchasing firm are lowered product costs when compared to local purchasing; however the firm will face significantly longer production lead times compared to the local supplier.

The effect of lead times has a significant impact in the order quantities from each supplier as they pose strict decision making points in the product ordering timeline. It is important to note that in our analysis, the order periods are based on the lead times given by the suppliers and we assume no delays in delivery time or unfulfilled orders.

To reiterate the problem, a firm faces uncertain time-dependent future consumer demand $X_{t}$ for a perishable/seasonal product. The firm has the ability to order $M$ units of the product at a cost of $C_{M}$ at time $t=0$ from the offshore supplier. Similarly, at a later date $(t=\tau)$ when the firm has a better view of the expected future demand, the firm has the option of ordering $U$ units of the product from the local supplier at a cost of $C_{U}$ where $C_{U}>C_{M}$. The firm is then able to sell this product to its customers for a price $P$. Considering excess inventory at the end of the season, the firm must sell the products at a discount price $P_{\text {Salv }}$. On the other hand, if consumer demand is not met and competitors enter the market, the firm faces a strategic cost $P_{\text {Strat }}$.

The following sections utilize the described manufacturers and order periods to determine optimal order quantities that would satisfy uncertain consumer demand. Initially, a single offshore single local order period model will be proposed where the firm has the ability to purchase from each supplier only once. Afterwards, a more practical, single offshore multiple 
local order period model will be discussed which utilizes dynamic programming to determine optimal local order quantities for many order periods with a single offshore order period. Finally, the relevancy of the Matching Method will be shown along with its application to industry.

\subsection{Single Offshore Single Local Order Period (SOSLOP) Model}

To maximize profit under uncertain consumer demad, we develop a psuedo-analytical dualsourcing stochastic model with multiple order periods. Initially, we consider only two order periods - a single offshore and single local order period (SOSLOP). Under the SOSLOP model, we assume a firm has to estimate at $t=0$ the future market demand $\left(X_{t}\right)$ faced at $t=T$. The future demand is assumed to be stochastic in nature with a known distribution supplied by managers or determined through historical analysis. Therefore at $t=0$, the firm has to make a decision on the order quantity from the offshore supplier $(M)$.

When $t=\tau$, the local order quantity $(U)$ has to be determined. At this point, the firm should also have a more confident view on the expected demand faced at time $t=T$, and has the option to order locally, clearly at a larger cost, to hedge the uncertainty in market demand. For the SOSLOP model, we consider only a single local order period at time $t=\tau$ to hedge against the offshore order; whereas in our more realistic SOMLOP model there can be multiple monthly orders from the local source, however the model would no longer be pseudo-analytical and will require numerical methods to solve.

The expected profit function faced by the retailer based on the order quantities $M$ at $t=0$ and $U$ at $t=\tau$ from the offshore and local manufacturers, respectively, can be represented by:

$$
\begin{array}{r}
\mathbb{E}[\operatorname{Profit}(M, U)]=\mathbb{E}\left[\min \left(X_{T}, M+U\right) P+P_{\text {Salv }} \cdot\left(M+U-X_{T}\right)^{+}\right. \\
\left.-P_{\text {Strat }} \cdot\left(X_{T}-M-U\right)^{+}-M C_{M}-U C_{U}\right]
\end{array}
$$

where $(\cdot)^{+}$indicates the maximum of the function enclosed in parantheses or zero. Equation 3.1 is shown as the expectation of a modified newsvendor equation and can be expanded into nested expectations based on order times $t_{0}$ and $\tau$ as shown in the following equation

$$
\begin{aligned}
\mathbb{E} & {[\operatorname{Profit}(M, U)]=} \\
& \mathbb{E}\left[-M C_{M}+\mathbb{E}_{\tau}[\underbrace{\min \left(X_{T}, M+U\right) P+P_{\text {Salv }} \cdot\left(M+U-X_{T}\right)^{+}-P_{\text {Strat }} \cdot\left(X_{T}-M-U\right)^{+}-U C_{U}}_{G\left(X_{T} ; M, U\right)}]\right] \\
= & \mathbb{E}\left[-M C_{M}+\mathbb{E}_{\tau}\left[G\left(X_{T} ; M, U\right)\right]\right]
\end{aligned}
$$

where $G\left(X_{T} ; M, U\right)$ is the profit function at time $t=\tau$. To simplify the notation of the SOSLOP model, financial discounting will not be applied during the formulation of the model, but is considered when comparing the results.

It is important to note that the order quantities from each of the suppliers is time dependent. 
Equation 3.1 has regularization terms $P_{\text {Strat }}$ and $P_{S a l v}$, which will affect the order quantities based on their values and the observable demand at the time of order. If $P_{\text {Strat }}<C_{U}-P_{\text {Salv }}$ then the order quantity from the onshore manufacturer at time $\tau$ will be less than the expected demand at time $t_{0}$ and what was already ordered from the offshore manufacturer $M$ i.e. $U<$ $\mathbb{E}_{t=0}\left[X_{T}\right]-M$. The rationale can be explained by the fact that lost sales have less of an impact on the company's profit compared to the purchase price from the offshore supplier. Similarly, if $P_{\text {Strat }}>C_{U}-P_{\text {Salv }}$ then $U>\mathbb{E}_{t=0}\left[X_{T}\right]-M$ and this shows that the cost of ordering extra units from the offshore supplier has less of an impact than the possibility of lost sales.

Working recursively, we can maximize the profit function $G\left(X_{T} ; M, U\right)$ based on the conditional probability density function of $X_{T}$ at time $t=\tau$ and $y=X_{\tau} ; f_{X \mid X_{\tau}}\left(x ; y=X_{\tau}\right)$. By taking the derivative of $G\left(X_{T} ; M, U\right)$ with respect to $U$ and setting it equal to zero, the optimal onshore order quantity $U^{*}$ can be determined for any value of $M$.

We can rewrite $\mathbb{E}_{\tau}\left[G\left(X_{T} ; M, U\right)\right]$ as

$$
\begin{aligned}
\mathbb{E}_{\tau}\left[G\left(X_{T} ; M, U\right)\right]=\int_{0}^{\infty} & {[\underbrace{\min (x, M+U) P}_{\mathrm{A} 1}+\underbrace{P_{\text {Salv }}(M+U-x)^{+}}_{\mathrm{A} 2}} \\
& -\underbrace{P_{\text {Strat }}(x-M-U)^{+}}_{\mathrm{A} 3}] f_{x \mid X_{\tau}}\left(x ; y=X_{\tau}\right) d x-\underbrace{U C_{U}}_{\mathrm{A} 4}
\end{aligned}
$$

and maximize the expected profit by taking the derivative with respect to $U$ and setting the equation equal to zero. Also note that although we want to capture the entire probability distribution in the function, the lower bound of the integral is zero. This is due to the fact that the expected consumer demand cannot decrease below zero, and naturally, the probability distribution function would have no support below zero.

Separating the equation into parts $A_{1}-A_{4}$ allows for easy management and solving. Beginning with $A_{1}$, the discontinuous nature of the equation makes it necessary to separate it into components where integration is possible as shown with,

$$
A_{1}=\int_{0}^{\infty}\left(1_{x<M+U} \cdot x+1_{x>M+U} \cdot(M+U)\right) \cdot P \cdot f_{x \mid X_{\tau}}\left(x ; y=X_{\tau}\right) d x .
$$

Next, taking the derivative of $A_{1}$ with respect to $U$ and integrating the function yields,

$$
\begin{aligned}
\frac{d A_{1}}{d U} & =\int_{\infty}^{\infty} 1_{x>M+U} \cdot P \cdot f_{x \mid X_{\tau}}\left(x ; y=X_{\tau}\right) d x \\
& =\int_{M+U}^{\infty} P \cdot f_{x \mid X_{\tau}}\left(x ; y=X_{\tau}\right) d x \\
& =P \cdot\left(1-F_{X_{T} \mid X_{\tau}}\left(M+U ; y=X_{\tau}\right)\right) .
\end{aligned}
$$


The same process is applied for parts $A_{2}-A_{4}$;

$$
\begin{aligned}
A_{2} & =\int_{0}^{\infty} P_{\text {Salv }} \cdot 1_{x<M+U} \cdot(M+U-x) \cdot f_{x \mid X_{\tau}}\left(x ; y=X_{\tau}\right) d x, \\
\frac{d A_{2}}{d U} & =\int_{\infty}^{\infty} P_{\text {Salv }} \cdot 1_{x<M+U} \cdot f_{x \mid X_{\tau}}\left(x ; y=X_{\tau}\right) d x \\
& =\int_{0}^{M+U} P_{\text {Salv }} \cdot f_{x \mid X_{\tau}}\left(x ; y=X_{\tau}\right) d x \\
& =P_{\text {Salv }} \cdot F_{X_{T} \mid X_{\tau}}\left(M+U ; y=X_{\tau}\right), \\
A_{3} & \left.=\int_{0}^{\infty} P_{\text {Strat }} \cdot 1_{x>M+U} \cdot(x-M-U)\right) \cdot f_{x \mid X_{\tau}}\left(x ; y=X_{\tau}\right) d x, \\
\frac{d A_{3}}{d U} & =-\int_{\infty}^{\infty} P_{\text {Strat }} \cdot 1_{x>M+U} \cdot f_{x \mid X_{\tau}}\left(x ; y=X_{\tau}\right) d x \\
& =-\int_{M+U}^{\infty} P_{S t r a t} \cdot f_{x \mid X_{\tau}}\left(x ; y=X_{\tau}\right) d x \\
& =-P_{S t r a t} \cdot\left(1-F_{X_{T} \mid X_{\tau}}\left(M+U ; y=X_{\tau}\right)\right), \\
A_{4} & =U C_{U}, \\
\frac{d A_{4}}{d U} & =C_{U}
\end{aligned}
$$

where $F_{X \mid Y}\left(M+U ; y=X_{\tau}\right)$ is the cumulative distribution function of $x$ at time $t=\tau$ and $y=X_{\tau}$.

Substituting Equations 3.5, 3.7, 3.9, 3.11 back into Equation 3.3 and isolating for $U$, allows us to determine the optimal onshore order quantity $U^{*}$, which maximizes the overall profit at time $t=\tau$

$$
U^{*}=\underbrace{F_{X_{T} \mid X_{\tau}}^{-1}\left(\frac{P+P_{\text {Strat }}-C_{U}}{P+P_{\text {Strat }}-P_{\text {Salv }}} ; y\right)}_{\gamma(y)}-M \equiv \gamma(y)-M .
$$

For convenience the term $\gamma(y)$ is introduced to represent the inverse cumulative distribution function of $X_{T}$ evaluated at the value $\frac{P+P_{\text {Strat }}-C_{U}}{P+P_{\text {Strat }}-P_{\text {Salv }}}$ at time $t=\tau$. The $\gamma(y)$ function resembles a modified newsvendor model, and will be used subsequently to solve for the optimal offshore order quantity $M$.

As expected, $U^{*}$ is largely dependent on the offshore order quantity $M$. With that in mind, it is important to take into account that $U^{*}$ in Equation 3.12 can be negative under large values of $M$. This can be explained under the circumstance where the retailer is short-selling the local units, since the assumption was previously made that the offshore unit cost is always less than onshore unit $\left(C_{M}<C_{U}\right)$. The strategy of short-selling locally produced units is not practical under our assumptions, and a more accurate representation of $U^{*}$ is

$$
U^{*}=(\gamma(y)-M)^{+}
$$


It is now possible to substitute the expression for $U^{*}$ into Equation 3.1 to determine the profit function at time $t=t_{0}$ based on the optimal local order quantity $U^{*}$,

$$
\begin{aligned}
\mathbb{E}\left[\operatorname{Profit}\left(M, U^{*}\right)\right]=\int_{\infty}^{\infty} & \underbrace{\min \left(X, M+(\gamma(y)-M)^{+}\right) P}_{\mathrm{B} 1}+\underbrace{P_{S a l v} \cdot\left(M+(\gamma(y)-M)^{+}-X\right)^{+}}_{\mathrm{B} 2} \\
& -\underbrace{P_{\text {Strat }} \cdot\left(X-M-(\gamma(y)-M)^{+}\right)^{+}}_{\mathrm{B} 3}] f_{x \mid X_{\tau}}\left(x ; y=X_{\tau}\right) d x \\
& \underbrace{-M C_{M}-(\gamma(y)-M)^{+} C_{U}}_{\mathrm{B} 4} .
\end{aligned}
$$

Following a procedure similar to the derivation of $U^{*}$, Equation 3.14 can be separated into parts $B_{1}-B_{4}$ and solved individually,

$$
\begin{aligned}
& B_{1}=\int_{0}^{\infty}\left(1_{x<M+U} \cdot x+1_{x>M+U} \cdot(M+U)\right) \cdot P \cdot f_{x \mid X_{\tau}}\left(x ; y=X_{\tau}\right) d x, \\
& B_{2}=\int_{0}^{\infty}\left(1_{x<M+U} \cdot(M+U-x)\right) \cdot P_{S a l v} \cdot f_{x \mid X_{\tau}}\left(x ; y=X_{\tau}\right) d x, \\
& B_{3}=\int_{0}^{\infty}\left(1_{x>M+U} \cdot(x-(M+U))\right) \cdot P_{\text {Strat }} \cdot f_{x \mid X_{\tau}}\left(x ; y=X_{\tau}\right) d x, \\
& B_{4}= \begin{cases}-M C_{M}-(\gamma(y)-M) C_{U} & \text { if } \gamma(y) \geq M \\
-M C_{M} & \text { if } \gamma(y)<M .\end{cases}
\end{aligned}
$$

Since the proposed functions are discontinuous, we must determine appropriate integration boundaries to the functions in Equation 3.15 , as can be seen for $B_{1}$ where

$$
B_{1}=\int_{0}^{\infty}\left(1_{x<M+U} \cdot x+1_{x>M+U} \cdot(M+U)\right) \cdot P \cdot f_{x \mid X_{\tau}}\left(x ; y=X_{\tau}\right) d x .
$$

Substituting $U^{*}$ for $U$ transforms the first part of the discontinuous function $\left(1_{x<M+U} \cdot x\right)$ into

$$
1_{x<M+(\gamma(y)-M)^{+}} \rightarrow\left\{\begin{array}{ll}
1_{x<\gamma(y)} & \text { if } \gamma(y) \geq M \\
1_{x<M} & \text { if } \gamma(y)<M
\end{array}=1_{\gamma(y)>M} \cdot 1_{x<\gamma(y)}+1_{\gamma(y)<M} \cdot 1_{x<M}\right.
$$

which exists under the conditions that demand is between $M$ and $\gamma(y)$ when $\gamma(y)$ is greater than $M$, or when demand is less than $M$ when $\gamma(y)$ is less than $M$, as shown in the following plot line
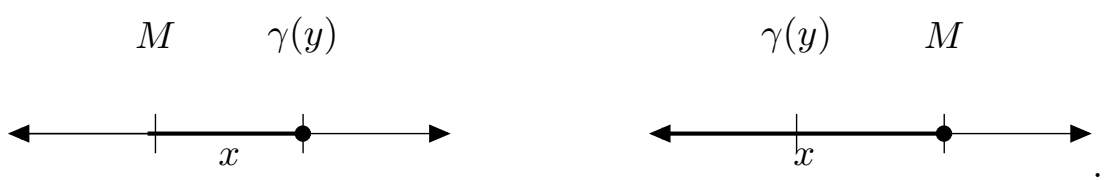
The second part of the discontinuous function $\left(1_{x>M+(\gamma(y)-M)^{+}}\right)$is handled in the same manner, initially by substituting $U^{*}$ for $U$, and then determining the integration boundaries:
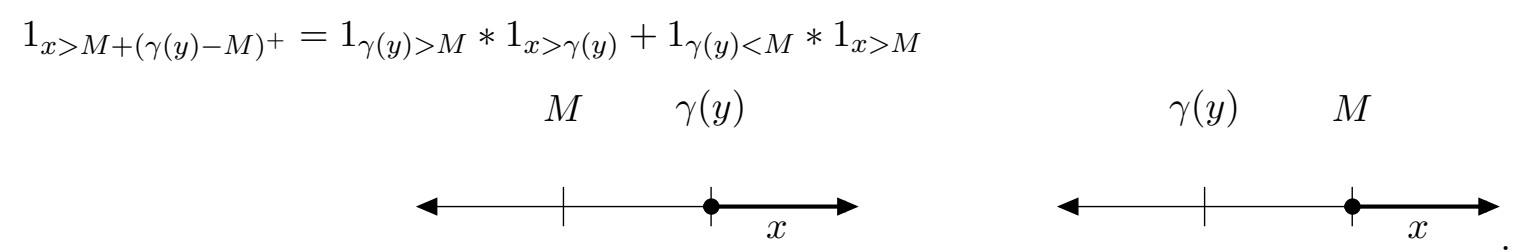

As a result, the function $B_{1}$ simplifies to:

$\therefore B_{1}=P \begin{cases}\int_{0}^{\gamma(y)} x * f_{x \mid X_{\tau}}\left(x ; y=X_{\tau}\right) d x+\int_{\gamma(y)}^{\infty} \gamma(y) * f_{x \mid X_{\tau}}\left(x ; y=X_{\tau}\right) d x & \text { if } \gamma(y) \geq M \\ \int_{0}^{M} x \cdot f_{x \mid X_{\tau}}\left(x ; y=X_{\tau}\right) d x+\int_{M}^{\infty} M \cdot f_{x \mid X_{\tau}}\left(x ; y=X_{\tau}\right) d x & \text { if } \gamma(y)<M .\end{cases}$

Applying a similar process, functions $B_{2}$ and $B_{3}$ simplify to

$$
\begin{gathered}
B_{2}=P_{\text {Salv }} \begin{cases}\int_{0}^{\gamma(y)}(\gamma(y)-x) \cdot f_{x \mid X_{\tau}}\left(x ; y=X_{\tau}\right) d x & \text { if } \gamma(y) \geq M \\
\int_{0}^{M}(M-x) \cdot f_{x \mid X_{\tau}}\left(x ; y=X_{\tau}\right) d x & \text { if } \gamma(y)<M\end{cases} \\
B_{3}=P_{\text {Strat }} \begin{cases}\int_{\gamma(y)}^{\infty}(x-\gamma(y)) \cdot f_{x \mid X_{\tau}}\left(x ; y=X_{\tau}\right) d x & \text { if } \gamma(y) \geq M \\
\int_{M}^{\infty}(x-M) \cdot f_{x \mid X_{\tau}}\left(x ; y=X_{\tau}\right) d x & \text { if } \gamma(y)<M .\end{cases}
\end{gathered}
$$

By defining $G(y ; a, b) \equiv \int_{a}^{b} x f_{x \mid X_{\tau}}\left(x ; y=X_{\tau}\right) d x$ we are able simplify the function $\int_{0}^{\gamma(y)}(\gamma(y)-$ $x) \cdot f_{x \mid X_{\tau}}\left(x ; y=X_{\tau}\right) d x$ such that

$$
\int_{0}^{\gamma(y)}(\gamma(y)-x) \cdot f_{x \mid X_{\tau}}\left(x ; y=X_{\tau}\right) d x \equiv \gamma(y) \cdot F(\gamma(y) ; y)-G(y ; 0, \gamma(y))
$$


Applying this process to Equations 3.16, 3.17, and 3.18, we are able to reduce $B_{1}-B_{3}$ to

$$
\begin{aligned}
& \therefore B_{1}=P \begin{cases}G(y ; 0, \gamma(y))+\gamma(y) \cdot(1-F(\gamma(y) ; y)) & \text { if } \gamma(y) \geq M \\
G(y ; 0, M)+M \cdot(1-F(M ; y)) & \text { if } \gamma(y)<M\end{cases} \\
& \therefore B_{2}=P_{\text {Salv }} \begin{cases}\int_{0}^{\gamma(y)}(\gamma(y)-x) \cdot f_{x \mid X_{\tau}}\left(x ; y=X_{\tau}\right) d x & \text { if } \gamma(y) \geq M \\
\int_{0}^{M}(M-x) \cdot f_{x \mid X_{\tau}}\left(x ; y=X_{\tau}\right) d x & \text { if } \gamma(y)<M\end{cases} \\
& =P_{\text {Salv }} \begin{cases}\gamma(y) \cdot F(\gamma(y) ; y)-G(y ; 0, \gamma(y)) & \text { if } \gamma(y) \geq M \\
M \cdot F(M ; y)-G(y ; 0, M) & \text { if } \gamma(y)<M\end{cases} \\
& \therefore B_{3}=P_{\text {Strat }} \begin{cases}\int_{\gamma(y)}^{\infty}(x-\gamma(y)) \cdot f_{x \mid X_{\tau}}\left(x ; y=X_{\tau}\right) d x & \text { if } \gamma(y) \geq M \\
\int_{M}^{\infty}(x-M) \cdot f_{x \mid X_{\tau}}\left(x ; y=X_{\tau}\right) d x & \text { if } \gamma(y)<M\end{cases} \\
& =-P_{\text {Strat }} \begin{cases}\gamma(y)[1-F(\gamma(y) ; y)]-\int_{\gamma(y)}^{\infty}(x) \cdot f_{x \mid X_{\tau}}\left(x ; y=X_{\tau}\right) d x & \text { if } \gamma(y) \geq M \\
M[1-F(M) ; y)]-\int_{M}^{\infty}(x) \cdot f_{x \mid X_{\tau}}\left(x ; y=X_{\tau}\right) d x & \text { if } \gamma(y) \geq M\end{cases} \\
& =-P_{\text {Strat }} \begin{cases}\gamma(y)-\gamma(y) \cdot F(\gamma(y) ; y)-G(y ; \gamma(y), \infty) & \text { if } \gamma(y) \geq M \\
M-M \cdot F(M ; y)-G(y ; M, \infty) & \text { if } \gamma(y)<M\end{cases}
\end{aligned}
$$

Rearranging and canceling out terms in the above expression reduces the profit function to Profit $= \begin{cases}\gamma(y) \cdot\left(P+P_{\text {Strat }}-C_{U}\right)+\gamma(y) \cdot F(\gamma(y) ; y) \cdot\left(P_{\text {Salv }}-P-P_{\text {Strat }}\right) & \\ -P_{\text {Strat }} \cdot G(y ; \gamma(y), \infty)+\left(P-P_{\text {Salv }}\right) \cdot G(y ; 0, \gamma(y))+M \cdot\left(C_{U}-C_{M}\right) & \text { if } \gamma(y) \geq M \\ M \cdot\left(P+P_{\text {Strat }}-C_{M}\right)+M \cdot F(M ; y) \cdot\left(P_{\text {Salv }}-P-P_{\text {Strat }}\right) & \\ +G(y ; 0, M) \cdot\left(P-P_{\text {Salv }}\right)-P_{\text {Strat }} \cdot G(y ; M, \infty) & \text { if } \gamma(y)<M .\end{cases}$ 
After some algebraic manipulation, the expected profit at $t=0$ can be determined as

$$
\begin{aligned}
\mathbb{E}[\text { Profit }(y)]=\int_{y=\gamma^{-1}(M)}^{\infty}[ & \gamma(y) \cdot\left(P+P_{\text {Strat }}-C_{U}\right)+\gamma(y) \cdot F(\gamma(y) ; y) \cdot\left(P_{\text {Salv }}-P-P_{\text {Strat }}\right) \\
& -P_{\text {Strat }} \cdot G(y ; \gamma(y), \infty)+\left(P-P_{\text {Salv }}\right) \cdot G(y ; 0, \gamma(y)) \\
& \left.+M \cdot\left(C_{U}-C_{M}\right)\right] f(y) d y+ \\
& \int_{y=0 \quad}^{\gamma^{-1}(M)}\left[M \cdot\left(P+P_{\text {Strat }}-C_{M}\right)+M \cdot F(M ; y) \cdot\left(P_{\text {Salv }}-P-P_{\text {Strat }}\right)\right. \\
& \left.+G(y ; 0, M) \cdot\left(P-P_{\text {Salv }}\right)-P_{\text {Strat }} \cdot G(y ; M, \infty)\right] f(y) d y .
\end{aligned}
$$

The equation for $\gamma^{-1}(M)$ is based on the underlying distribution or stochastic process that is used to approximate the uncertain demand. The following process shows an example of the derivation of $\gamma^{-1}(M)$ assuming a normal distribution,

$$
\begin{aligned}
F\left(M+U^{*}(y), y\right) & =\frac{P+P_{\text {Strat }}-C_{U}}{P+P_{\text {Strat }}-P_{\text {Salv }}} \\
\frac{1}{2}+\frac{1}{2} \operatorname{erf}\left(\frac{M+U^{*}(y)-y}{\sigma \sqrt{2}}\right) & =\frac{P+P_{\text {Strat }}-C_{U}}{P+P_{\text {Strat }}-P_{\text {Salv }}} \\
U^{*}(y) & =\underbrace{y+\sigma \sqrt{2} \cdot \operatorname{erf}^{-1}\left[2\left(\frac{P+P_{\text {Strat }}-C_{U}}{P+P_{\text {Strat }}-P_{\text {Salv }}}\right)-1\right]}_{\gamma(y)}-M
\end{aligned}
$$

and noting that $\gamma(y)$ has to be greater than $\mathrm{M}$ allows us to rearrange the equation to:

$$
\gamma^{-1}(M)=M-\sigma \sqrt{2} * e r f^{-1}\left[2\left(\frac{P+P_{\text {Strat }}-C_{U}}{P+P_{\text {Strat }}-P_{\text {Salv }}}\right)-1\right] .
$$

Since the $\gamma(y)$ function is distribution-specific, the extent to which a solution for the optimal offshore order quantity $M^{*}$ can be found is limited, and thus a psuedo-analytical equation is proposed.

Differentiating Equation 3.24 with respect to $M$ and setting it equal to zero provides us with a final psuedo-analytical expression for the optimal offshore order quantity $M^{*}$

$$
0=C_{U}-C_{M}+\left(P+P_{\text {Strat }}-C_{U}\right) \cdot F\left(\gamma^{-1}(M)\right)-\left(P-P_{\text {Salv }}-P_{\text {Strat }}\right) \int_{0}^{y=\gamma^{-1}(M)} F(M ; y) f(y) d y
$$

Simple numerical methods techniques can be used to fully solve Equation 3.26 for any given $\gamma(y)$. 


\subsection{Single Offshore Multiple Local Order Period (SOMLOP) Mod- el}

In this section, a more practical SOMLOP model with multiple local order quantities will be introduced. This model alters the SOSLOP model by allowing the managers to not only modify the amount of times they order locally, but also give them the ability to modify the underlying distribution based on their industry expertise through the Matching Method developed by [Jaimungal and Lawryshyn, 2016], discussed more thoroughly in the next section.

In the SOMLOP model we assume that selling season lasts $n$ months where now the final profit realization month $T=T_{n}$, and $T_{n-i}$ represents a time $i$ months prior to the profit realization month. Under the SOMLOP scenario, the firm makes a places an order for $M$ units of product from the offshore manufacturer at $t=0$, where the orders are placed at the end of the month and arrive dependent on the supplier's specified lead times. We assume that five months prior to the profit realization month $\left(t=T_{n-5}\right)$, the firm has the option to place a local order quantity $U$ to hedge against the uncertain consumer demand. Assuming a lead time of one month from the local supplier, the firm then has the option to order locally and hedge once again the next month $\left(t=T_{n-4}\right)$. The local hedging process continues in this manner for as long as the firm desires until $T_{n}$. This model also assumes that the firm has multiple selling periods to coincide with the local order periods. The firm has the ability to sell their goods during the months it plans to hedge locally, and then make an order decision at the end of the month to replenish their inventory.

One month prior to the final profit realization month $\left(t=T_{n-1}\right)$, the firm can no longer place orders from the local supplier as the supplier's lead times dictate that the product will arive after the end of the selling period. The expected profit at $T_{n-1}$, based on uncertain consumer demand $X$ and the firm's inventory level $I$, can be easily calculated using the process from Equation 3.1 with modifications to the function to yield

$$
\begin{aligned}
& \mathbb{E}\left[\text { Profit }_{n-1} \mid X_{n-1}, I_{n-1}\right]= \\
& \mathbb{E}\left[\min \left(X_{n}, I_{n}\right) \cdot P+P_{\text {Salv }} \cdot\left(I_{n-1}-X_{n-1}\right)^{+}-P_{\text {Strat }} \cdot\left(X_{n-1}-I_{n-1}\right)^{+}\right] \cdot e^{-r(T-\tau \cdot(n-1))} .
\end{aligned}
$$

Clearly, the expected profit at $T_{n-1}$ is dependent on the current and next months' uncertain demand and inventory levels discounted to $T_{n-1}$. Also visible is the effect of increasing the number of order quantities in the model. Monthly expected profit solutions become overly complicated due to nested dependencies and distributions, and therefore, the SOMLOP model will be solved using Monte-Carlo simulations with dynamic programming.

Consider a grid at time $t=T_{n}$ with product demand $X$ and inventory stock $I$ increasing in the $x$ and $y$ axes respectively as per Figure 3.1. Following Equation 3.27, we can then determine the expected profit at any given inventory and expected demand for month $T_{n-1}$. 


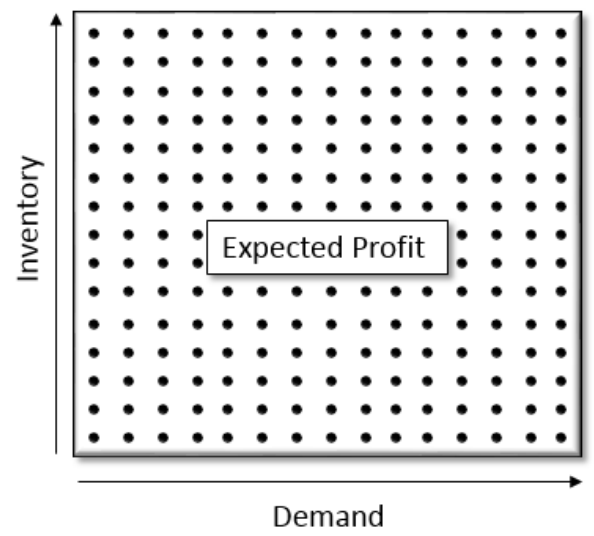

Figure 3.1: Monthly expected profit grid

Now, working recursively we can calculate the maximum expected profit Profit* at each inventory and demand coordinate in the previous months $\left(T_{n-2}, T_{n-3}, \ldots, T_{n-i}\right)$ with a modified profit function. For example, consider the following equation used to determine the maximum expected profit for $T_{n-2}$ :

$$
\begin{aligned}
\operatorname{Profit}_{n-2}^{*}\left(X_{n-2}, I_{n-2}\right)= & \max _{U_{n-1}}\left(\mathbb{E}\left[\text { Profit }_{n-2}\right]\right) \\
= & \max _{U_{n-1}}\left(\mathbb{E}\left[\text { Profit }_{n-1} \mid X_{n-1}, I_{n-1}\right]+\mathbb{E}\left[\min \left(X_{n-1}, I_{n-1}\right) \cdot P\right.\right. \\
& \left.\left.-P_{\text {Strat }} \cdot\left(X_{n-1}-I_{n-1}\right)^{+}-U_{n-1} \cdot C_{U}\right]\right) \cdot e^{-r(T-\tau \cdot(n-1))}
\end{aligned}
$$

where $I_{n-1}=\left(I_{n-2}-X_{n-1}\right)^{+}+U_{n-1}$.

Equation 3.28 differs from Equation 3.27 in two major ways. First, for the months prior to the final profit realization month, the firm has the option of ordering products locally, shown by the introduction of the $U$ term in the function. Second, assuming an unlimited inventory capaity, we are disregarding the possibility of overstocking, and therefore, the possibility of salvaging the product. This is done because the excess product that was not sold in this order period can be kept in capacity to sell for future order periods, increasing the inventory supply and effectively decreasing the next order period's order quantity.

As mentioned before, the Equation 3.28 can be applied for any month $i$ prior to $T_{n-1}$ such that

$$
\begin{aligned}
\operatorname{Profit}_{n-i}^{*}\left(X_{n-i}, I_{n-i}\right)= & \max _{U_{n-i}}\left(\mathbb{E}\left[\text { Profit }_{n-i}\right]\right) \\
= & \max _{U_{n-i+1}}\left(\mathbb{E}\left[\text { Profit }_{n-i+1} \mid X_{n-i+1}, I_{n-i+1}\right]+\mathbb{E}\left[\min \left(X_{n-i+1}, I_{n-i+1}\right) \cdot P\right.\right. \\
& \left.\left.-P_{\text {Strat }} \cdot\left(X_{n-i+1}-I_{n-i+1}\right)^{+}-U_{n-i+1} \cdot C_{U}\right]\right) \cdot e^{-r(T-\tau \cdot(n-i+1))}
\end{aligned}
$$


where $I_{n-i+1}=\left(I_{n-i}-X_{n-i+1}\right)^{+}+U_{n-i+1}$. The profit function shown in Equation 3.29 is challenging to solve numerically when considering nested dependencies and therefore has to be optimized through simulation for months prior to $T_{n-1}$.

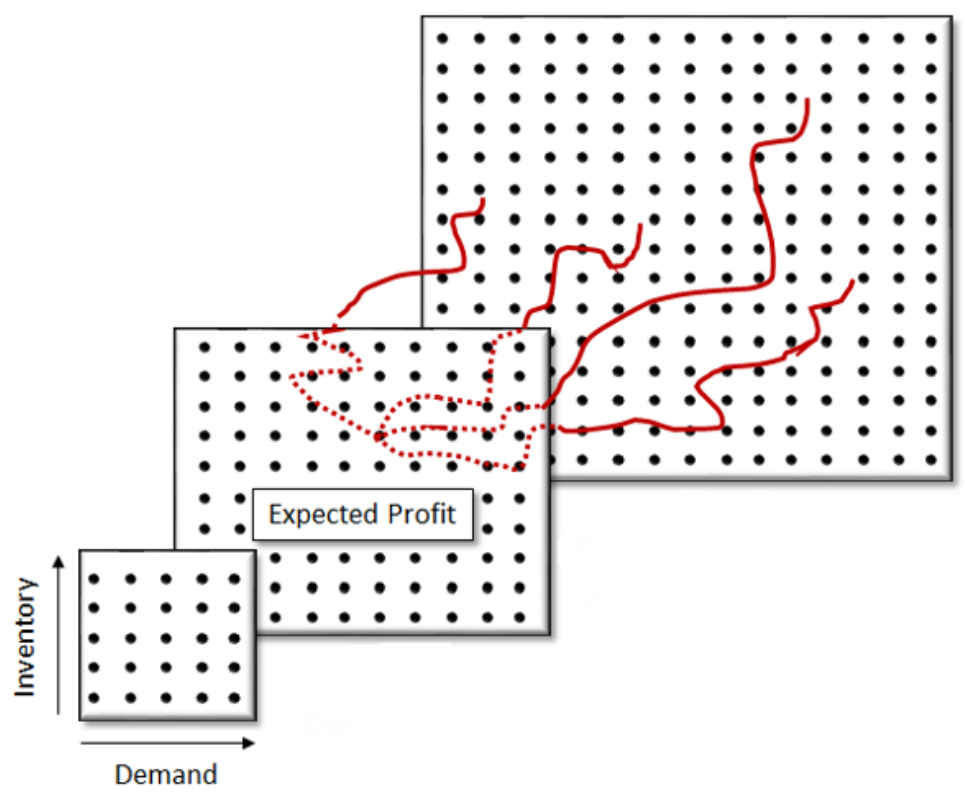

Figure 3.2: Expected profit calculation process, based on previous month's inventory level and expected demand

At each inventory level and expected demand coordinate point at month $T_{n}-i$, the expected demand at month $T_{n-i+1}$ can be estimated through GBM simulation. By knowing the current inventory level at month $T_{n-i}$ and the expected demand faced in month $T_{n-1+1}$, we are able to determine the expected profit for a single simulation path and coordinate location in month $T_{n}-i$, since this profit grid for month $T_{n-i+1}$ would already be known. By generating many paths from a single coordinate point in month $T_{n}-i$, as shown in Figure 3.2 for $T_{n-2}$, and optimizing Equation 3.29 with respect to $U$, the expected profits can be averaged to produce the maximum expected profit for a single coordinate. Repeating the above process for all of the inventory level and expected demand coordinates in the month, and then iterating the months, will yield a complete grid of maximum expected profits faced in the selling season.

As a result, Equation 3.29 indirectly solves for the optimal local order quantities $U^{*}$ that maximize the expected profit. Furthermore, when $i=n$ Equation 3.29 will maximize the expected profit for the first month and will change to 


$$
\begin{aligned}
\operatorname{Profit}_{T_{n-n}}^{*}\left(X_{T_{n-n}}, I_{T_{n-n}}\right)= & \max _{M_{n-n}}\left(\mathbb{E}\left[\text { Profit }_{n-n}\right]\right) \\
= & \max _{U_{n-n+1}}\left(\mathbb{E}\left[\text { Profit }_{n-n+1} \mid X_{n-n+1}, I_{n-n+1}\right]+\mathbb{E}\left[\min \left(X_{n-n+1}, I_{n-n+1}\right) \cdot P\right.\right. \\
& \left.\left.-P_{S t r a t} \cdot\left(X_{n-n+1}-I_{n-n+1}\right)^{+}-M_{n-n+1} \cdot C_{M}\right]\right) \cdot e^{-r(T-\tau \cdot(n-n+1))}
\end{aligned}
$$

and can be used to determine the optimal offshore order quantities $M^{*}$.

\subsection{Incorporation of the Matching Method}

As previously mentioned, the Matching Method was developed as a means of allowing managers the ability to use their expertise and match what they believe to be accurate cash-flow estimates to those of stochastic processes; the details of which can be found in Jaimungal and Lawryshyn, 2016]. For our research, the underlying stochastic process could be related to market trends or historical weather conditions and the Matching Method will be incorporated to help the managers decide on their order volume without the need for managers fully understanding the underlying stochastic process.

Typically, operation managers have little knowledge about the underlying stochastic process in their field of expertise. It is difficult for an analyst to ask the managers what they believe to be an accurate drift or volatility parameter for their process, and usually managers tend to be skeptical of results generated through a procedure they do not understand. As experts in their field, operation managers know historical trends and can provide insight on order quantities. In the most simplistic situation, a manager will have the ability to provide pessimistic, likely, and optimistic consumer demand quantities for future months based on their expertise.

Referring to Figure 1.1, let's assume that the distributions show the underlying stochastic process modeled as a geometric Brownian motion 


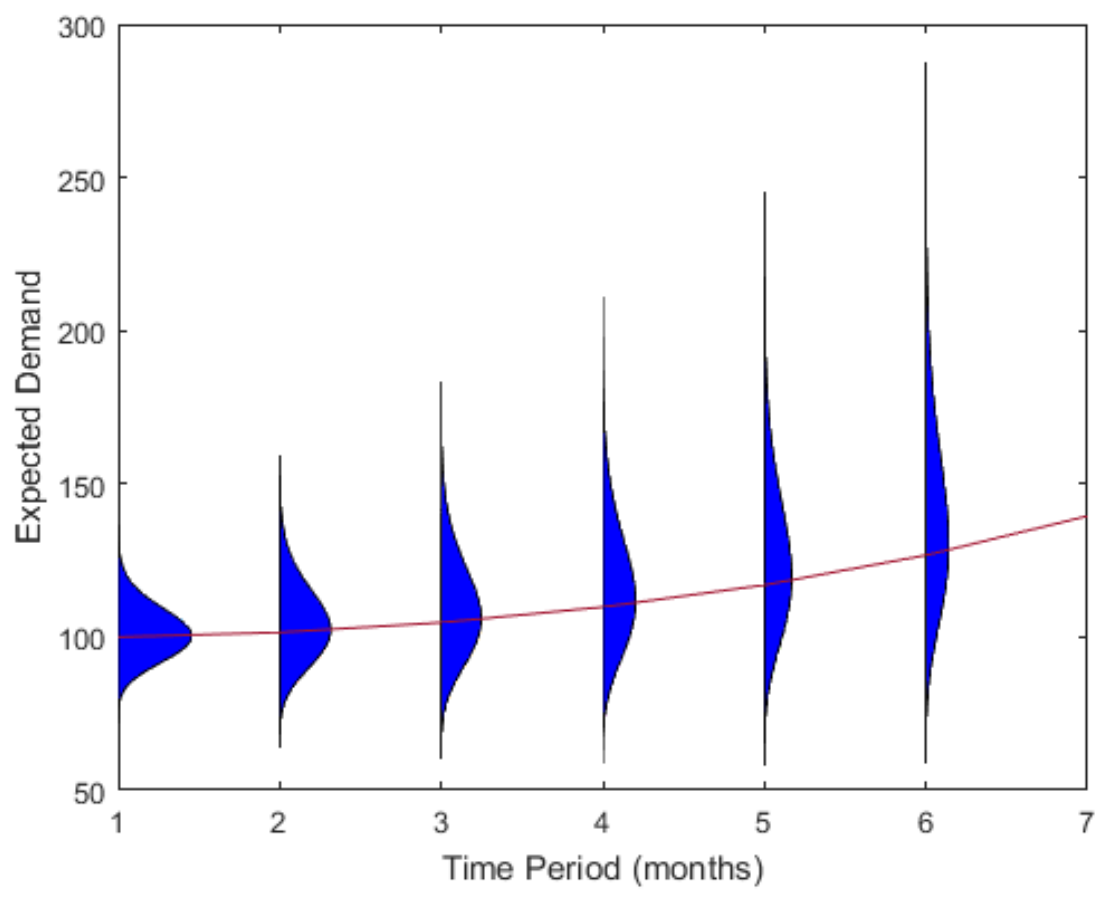

Figure 1.1. Effect of Drift on Future Expected Demand

We can see demand tending to increase, but estimates further into the future are becoming worse because of the diffusion and volatility of the system. Table 3.1 shows an example of what industry managers might provide with respect to monthly consumer demands. The managers understand that in Month 1, the firm should expect a consumer demand of 106 units - but can be as high as 136 units or as low as 75 .

\begin{tabular}{|l|c|c|c|}
\hline \multirow{3}{*}{ Month 1 } & Optimistic & Likely & Pessimistic \\
\cline { 2 - 4 } & 136 & 106 & 75 \\
Month 2 & 139 & 95 & 64 \\
Month 3 & 141 & 113 & 55 \\
Month 4 & 153 & 74 & 52 \\
Month 5 & 177 & 77 & 57 \\
Month 6 & 223 & 89 & 53 \\
\hline
\end{tabular}

Table 3.1: Expected Monthly Managerial Estimates $\left(V_{k}\right)$

The information provided by the managers can be transformed into a set of fuzzy triangular distributions to mimic the manager's insights as shown in Figure 3.3 . So while the manager assumes the depicted triangular distribution as appropriate estimates of expected monthly demand, the underlying stochastic process follows that shown in Figure 1.1 with the red line representing the same mean expected demand in both cases. 


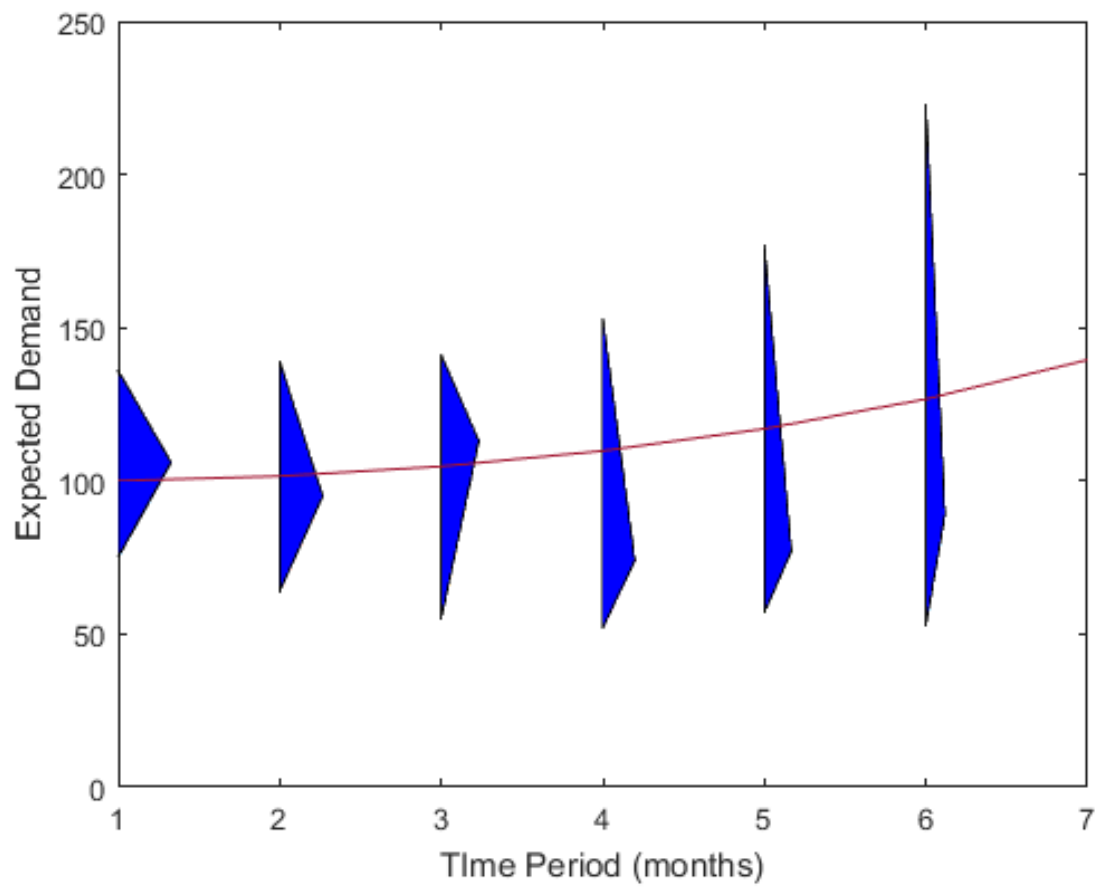

Figure 3.3: Expected Monthly Fuzzy Demand

The concept of the Matching Method allows integration of managerial insights to those of the underlying stochastic driver. It is possible to map the underlying probability distribution function expected demands $X$ at times $T_{k}: k=1, \ldots, n$ through a transformation function $\varphi(\cdot)$ to match managerial estimates $V_{k}: k=1, \ldots, n$ so that

$$
V_{k}=\varphi_{k}\left(X_{T k}\right)
$$

Therefore, the transformation function $\varphi(X)$ that produces the manager-specified distributions $F_{k}^{*}(v)$ noted in Table 3.1 for the uncertain consumer demands at time $T_{k}$, is given by

$$
\varphi_{k}(X)=F_{k}^{*-1}\left(F\left(T_{k}, X\right)\right)
$$

where, for the GBM case, we have $F(T, X)=\Phi(z(T, X))$ with $\Phi$ being the standard normal cdf and

$$
z(T, X)=\frac{1}{\sigma \sqrt{T}} \ln \frac{X}{X_{0}}-\frac{\left(\mu-\frac{1}{2} \sigma^{2}\right)}{\sigma} \sqrt{T}
$$




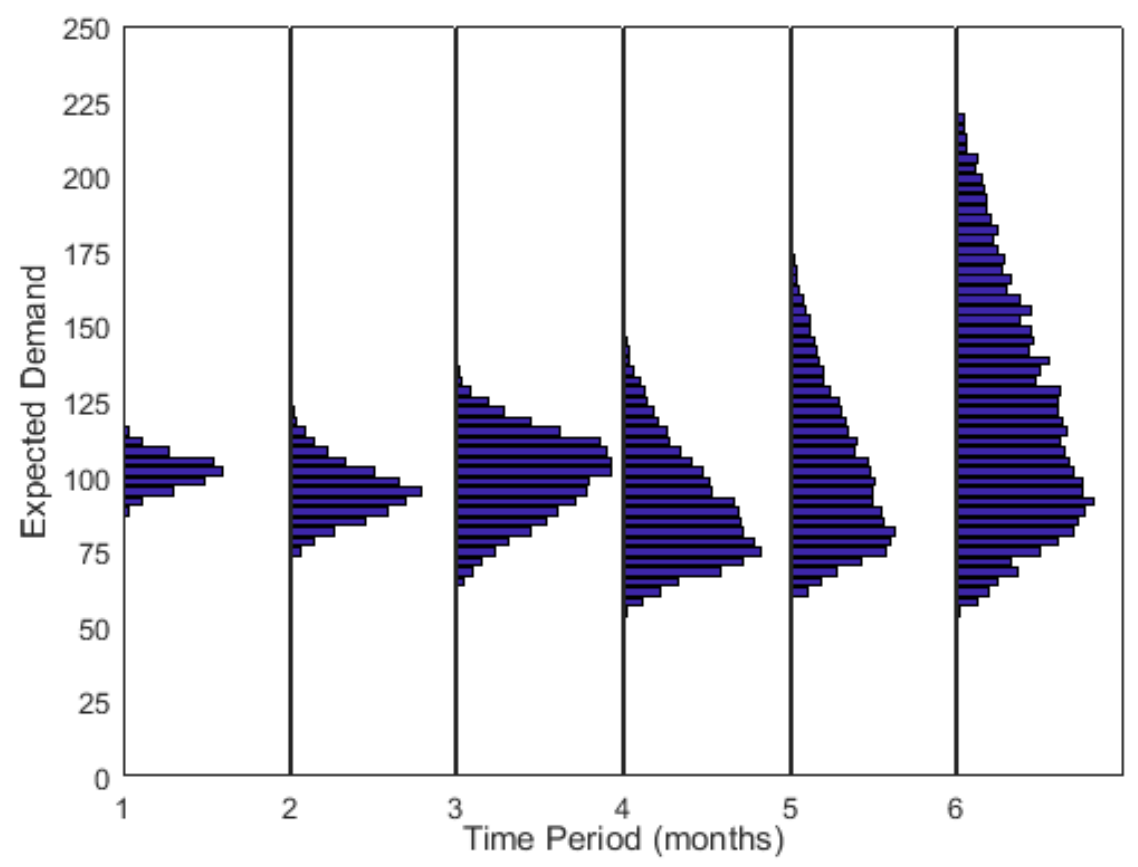

Figure 3.4: Histogram of Underlying Stochastic Process Matched with Managerial Estimates; $\mu=0.2, \sigma=0.3, X_{0}=100, T=6 / 12$

Figure 3.4 shows the result of the expected monthly demand when the stochastic driver is matched with managerial estimates using 10,000 random normally distributed numbers for simulation. Clearly, the matched distributions are triangular in shape as expected, but also contain the traces of the stochastic driver. Taking a look at Month 1, the managerial estimates have an optimistic expected demand of 136 units whereas the driving process is more concentrated around the mean, reaching only as high as 125 units with decent probability. The matched histogram shows that both the manager and underlying distributions expect a mean close to 100 and based on the underlying process, the manager's optimistic estimate of 136 units is unlikely to be met. Therefore, the firm should expect a customer demand of roughly 100-110 units in the first month. Looking at Month 6, the diffusion of the underlying driver shows that expected demand can reach almost 300 units, while the manager knows it will not exceed 223 units. This is once again captured in the matched histogram by limiting the distribution's tail ends.

In this demonstration, a simple triangular (fuzzy) distribution was used to simulate managerial estimates. For practical use, as with the rest of this research, there is no limitation to the distribution provided by the managers. By incorporating managerial estimates with the underlying stochastic driver, the Matching Method helps with decision making that accurately reflects the input of industry experts. In the following chapter, the Matching Method will not be utilized, and instead the SOSLOP and SOMLOP models will be tested to determine how various parameters affect their performance, and establish if there is a value to dual-sourcing. 


\section{Chapter 4}

\section{Results}

In this chapter, results pertaining to both the psuedo-analytical SOSLOP model and the more realistic SOMLOP model will be discussed. Initially, the effects of important factors such as the underlying distribution along with its parameters will be observed on the effect of the psuedoanalytical model. Then, the benefits and drawbacks of the simulated, multi-order model will be compared to the analytical case.

Once again, one of the novelties in this research is the ability for managers and industry leaders to use their knowledge and expertise by supplying underlying information as to how they believe the demand will materialize in the future. For the following results, unless otherwise mentioned, the underlying stochastic process used to estimate the future expected demand of the product will be a GBM process, which follows the stochastic differential equation

$$
d X(t)=\mu X(t) d t+\sigma X(t) d W(t)
$$

where $\mu$ and $\sigma$ are the linear drift and diffusion coefficients of the process and the Wiener process $W(t)$ is the stochastic process itself.

Solving the stochastic differential equation through the application of Itô's lemma yields the solution

$$
X(t)=x_{0} e^{\left(\mu-\frac{1}{2} \sigma^{2}\right) t+\sigma W(t)}
$$

which shows that $X(t)$ is lognormally distributed with

$$
\begin{aligned}
& \text { mean } & \mathbb{E}(X(t)) & =x_{0} e^{\mu t} \\
& \text { variance } & \operatorname{var}(X(t)) & =x_{0}^{2} e^{2 \mu t}\left(e^{\sigma^{2} t}-1\right) \\
& \text { density } & f(t, x) & =\frac{1}{\sigma x \sqrt{2 \pi t}} e^{-\left(\log x-\log x_{0}-\left(\mu-\frac{1}{2} \sigma^{2}\right) t\right)^{2} / 2 \sigma^{2} t} .
\end{aligned}
$$




\begin{tabular}{|c|c|c|c|c|c|c|c|}
\hline 0 & 5 & 10 & 15 & 20 & 25 & 30 & 35 \\
\hline 49.94083 & 44.94083 & 39.94083 & 34.94083 & 29.94083 & 24.94083 & 19.94083 & 14.94083 \\
\hline
\end{tabular}

Table 4.1: Optimal local order quantity $U^{*}$ with changing offshore order quantities $M$

\subsection{Optimal Local Order Quantity}

Just as the model was constructed, initially the accuracy of the equation used to calculate the optimal local order quantity $\left(\mathrm{U}^{*}\right)$ will be analyzed. Using Equation 3.12 and applying the geometric Brownian motion assumption, the results for the simulated Monte-Carlo scenario with varying offshore order quantities $M$ can be seen in Figure 4.1 .

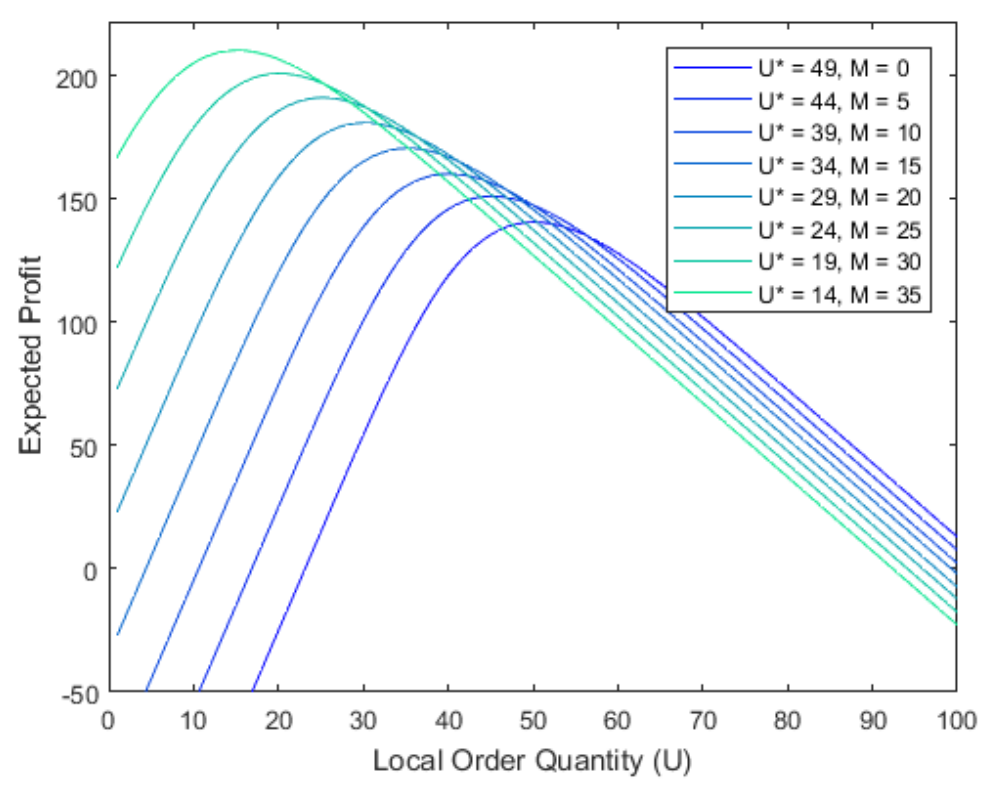

Figure 4.1: Simulated optimal local order quantity $U^{*}$ with changing offshore order quantities $M$

$P=10, P_{\text {Salv }}=3, P_{\text {Strat }}=4, C_{U}=6, C_{M}=4, \tau=6 / 12, X_{0}=40$

To ensure the accuracy of the simulated scenario, the simulation was completed using 20,000 randomly normal distributed numbers to simulate the stochastic Wiener process. The local order quantity $U$ that resulted in the largest expected profit dependent on the offshore order quantity $M$ was used as the optimal local order quantity $U^{*}$ through simulation. Table 4.1 compares simulated results to those generated with Equation 3.12, and it can be seen that the optimal local order quantities align with the simulated scenario. 


\subsection{Performance of SOSLOP Model}

In this section, the psuedo-analytical SOSLOP model will be evaluated to show how various parameters/inputs affect the expected profit of the system. It has been shown that Equation 3.12 performs accurately at low values of the diffusion parameter $\sigma$. Therefore, the following results will utilize Equation 3.12 to calculate the optimal local order quantities $U^{*}$ and the optimal offshore order quantities $M^{*}$ will be found through simulation. The process used to find the optimal offshore order quantities is similar to that described in the previous section when analyzing the performance of 3.12 - the optimal offshore order quantity is that which provides the highest expected profit under the given conditions.

Much of the accuracy of this model is determined by choosing an appropriate stochastic process. Figure 4.2 shows the importance of choosing a distribution which best represents the expected demand of the underlying asset. Running the model, all parameters were kept constant, modifying only the underlying process between a Standard Brownian Motion with drift which uses a normal distribution and the aforementioned geometric Brownian motion with both having a varying initial expected demand $X_{0}$.

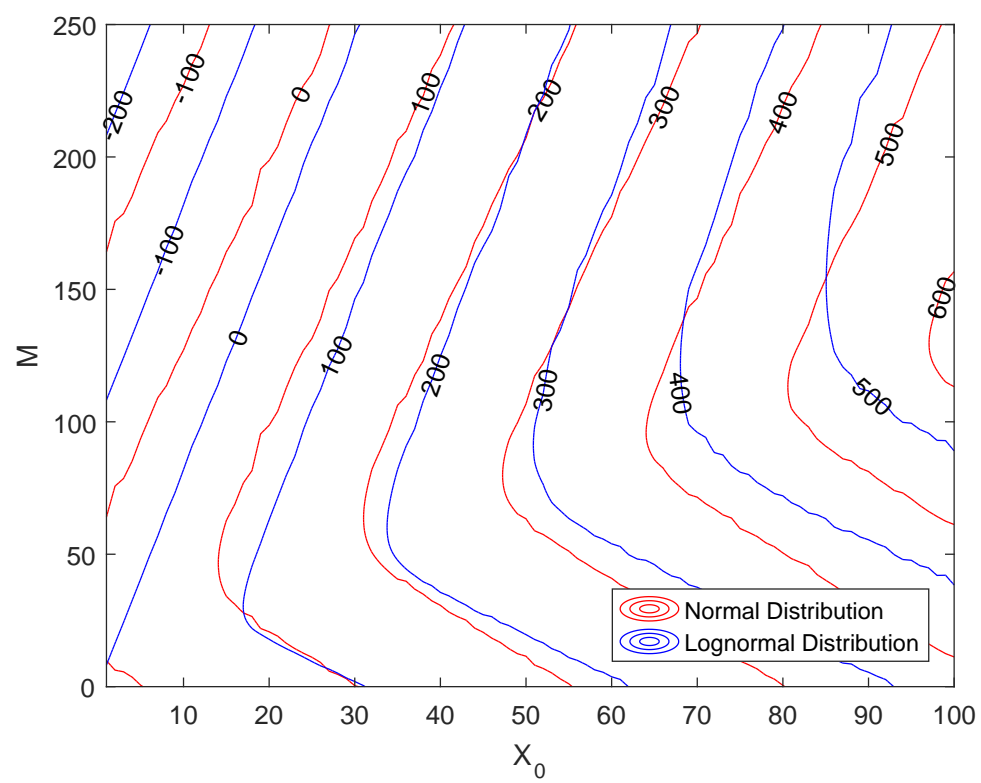

Figure 4.2: Expected profit contours based on underlying distribution type: Normal (Standard Brownian Motion) vs Lognormal (Geometric Brownian Motion) $P=10, P_{\text {Salv }}=3, P_{\text {Strat }}=4, C_{U}=6, C_{M}=4, T=5 / 12, \tau=2 / 12, \mu=0.2, \sigma=0.3$

The expected profit contours based on the initial expected demand and varying offshore production quantities $(M)$ fluctuates greatly depending on the distribution used. This is especially true with increasing initial expected demand, as the contours between chosen distributions begin to cross boundaries and can provide highly inaccurate results. It is imperative that the users of this model understand the expected behaviour of their underlying asset either through 
historical experience or by applying an accurate stochastic process.

Alongside, the implied drift $\mu$ and volatility $\sigma$ also have an effect on the expected profit, similar to the effect on finding the optimal local order quantity $U^{*}$. Using a normal distribution while modifying drift and volatility, Figure 4.3 shows a contour of the expected profit with respect to the initial expected demand $X_{0}$.

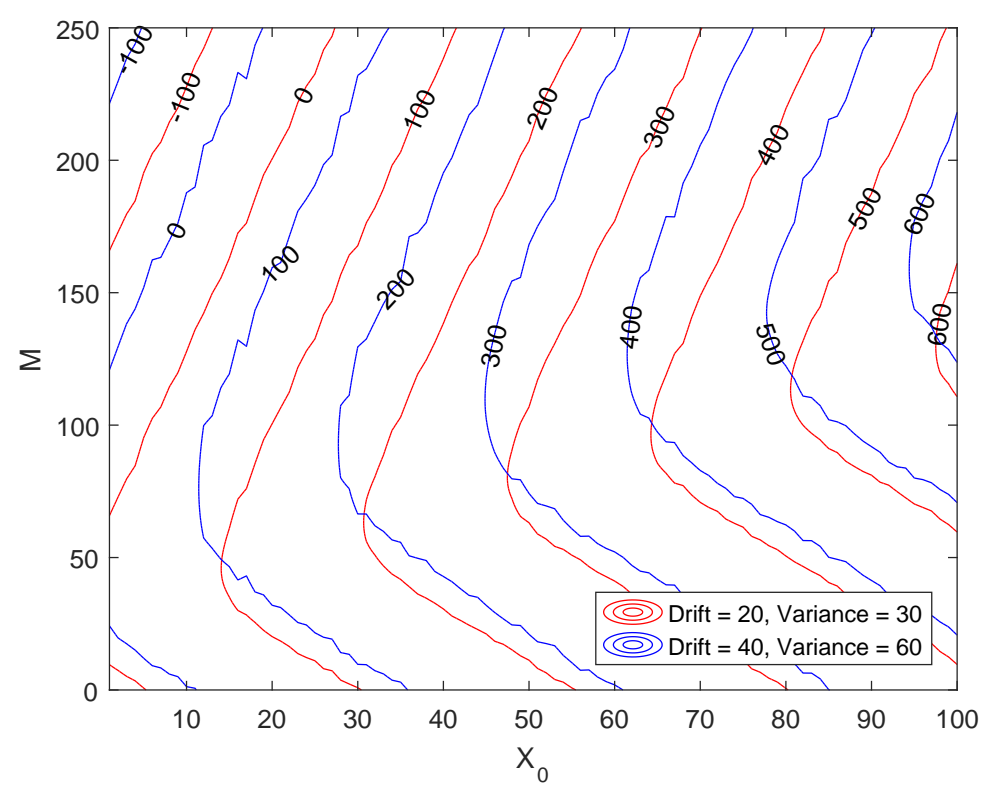

Figure 4.3: Effect of drift and volatility on expected profit

As expected, an increase in drift will typically lead to an increase in the expected profit under constant $X_{0}$ and $M$. This can be explained by the fact that the retailer is expecting a sharper increase in demand as time progresses, as is noticed by seasonal items and much less so for year-round goods. Increasing volatility increases the uncertainty in expected profit and a large diffusion parameter causes disturbances in pinpointing the optimal offshore and onshore order quantities.

Figure 4.4 shows the correlation of offshore and local order quantities based on initial expected demand at time $t=0$ on the expected profit of the system. From the figures, it is clearly noticeable that as initial expected demand increases, more units should be ordered from the offshore source to maximize the expected profit. However as shown in Figure 4.4a, the optimal offshore order quantity $(M)$ denoted by the red line, is always less than the amount that would provide maximum expected profit. This behaviour is exactly the aim of this research as it provides operational hedging for firms by preventing over-ordering and potentially large losses in profit if the consumer demand does not meet expectations.

To make up for the lower-than-needed orders from the offshore manufacturer, the local source is utilized at time $t=\tau$. As demonstrated in Figure 4.4b, if the firm follows the prescribed inventory policy and orders the optimal amount from the offshore source, then there exists a 
non-zero optimal local order quantity $(U)$ to hedge against the uncertain consumer demand.

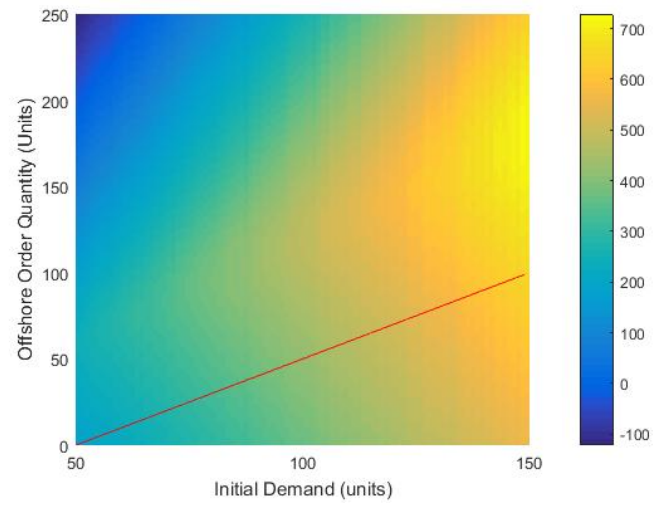

(a) Expected Profit with Optimal Offshore Order Quantity

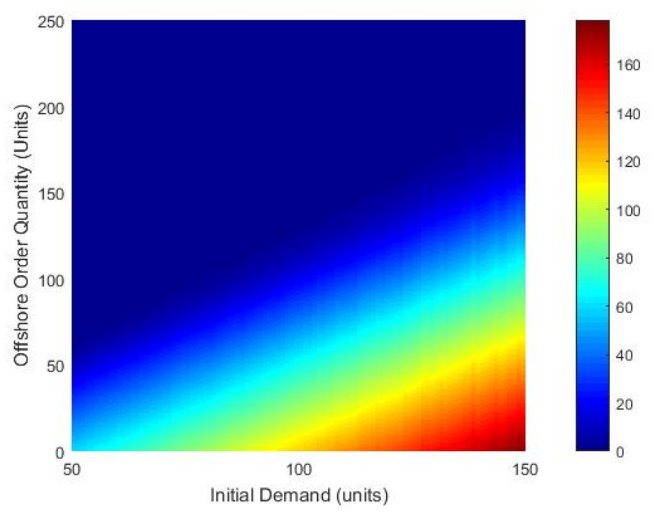

(b) Optimal Local Order Quantity

Figure 4.4: Optimal Offshore and Local Order Quantities;

$\mu=0.2, \sigma=0.3, T=\frac{9}{12}, \tau=\frac{5}{12}, C_{U}=6, C_{M}=5, P=10, P_{\text {Strat }}=4, P_{\text {Salv }}=3$

The SOSLOP model does have its limitations. For example, when $C_{U}=P_{S a l v}$, the expected profit is undefined and approaches infinity as can be seen in Figure 4.5a. This behaviour is expected and consistent with Equation 3.12 as the inverse cumulative distribution function simplifies to $F_{X \mid X_{\tau}}^{-1}(1 ; y)=\infty$. The practical explanation for this scenario is that the firm will buy infinite amount of product from the local source to make certain that the consumer demand is always met; the firm is not worried about excess inventory levels because they can salvage the inventory for the same price as was purchased from the local supplier effectively creating infinite profit.

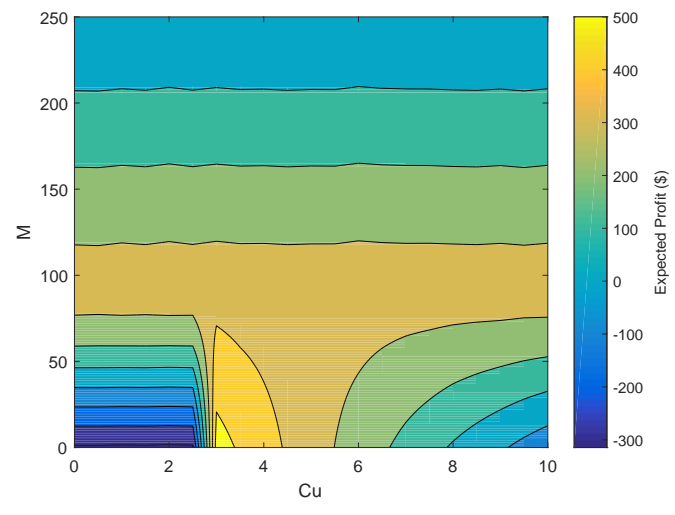

(a) $P_{\text {Salv }}=2.75, C_{M}=5, P=10$

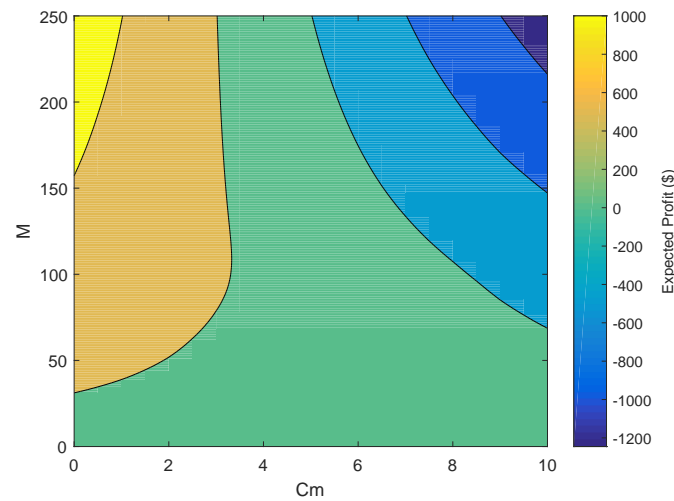

(b) $P_{\text {Salv }}=2.75, C_{U}=5, P=10$

Figure 4.5: Expected profit contour

For low values of $C_{U}\left(C_{U}<P_{\text {Salv }}\right)$, the offshore order quantity $M$ has a much higher impact on the expected profit. When the local production cost is less than the salvage value, ordering 
a small quantity of units from the offshore source causes a large loss in potential profit. And as expected, it can also be seen that the offshore order quantity has little to no effect on the expected profit when the offshore and local production costs are equal $\left(C_{U}=C_{M}\right)$.

In contrast, the offshore production cost $C_{M}$ is not limited by the salvage value of the asset as shown in Figure 4.5b. The expected profit based on the offshore production price behaves conventionally, providing maximum profit when $C_{M}$ is minimized and dependent on the offshore order quantities $M$.

The local order time $\tau$ and end time $T$ have little effect on the maximum expected profit as shown in Figure 4.6 under most circumstances. Only in the case where the local order time is equal to the the end time $(\tau=T)$, does the maximum expected profit drop significantly as shown by the large downward spikes in profit. This is because the time the local order is placed is typically based on the lead time set by the local manufacturer. Therefore, orders placed at a time where $\tau=T$ cause a large decrease in maximum expected profit because the goods cannot be manufactured instantaneously and the retailer is effectively not taking advantage of the hedging option.

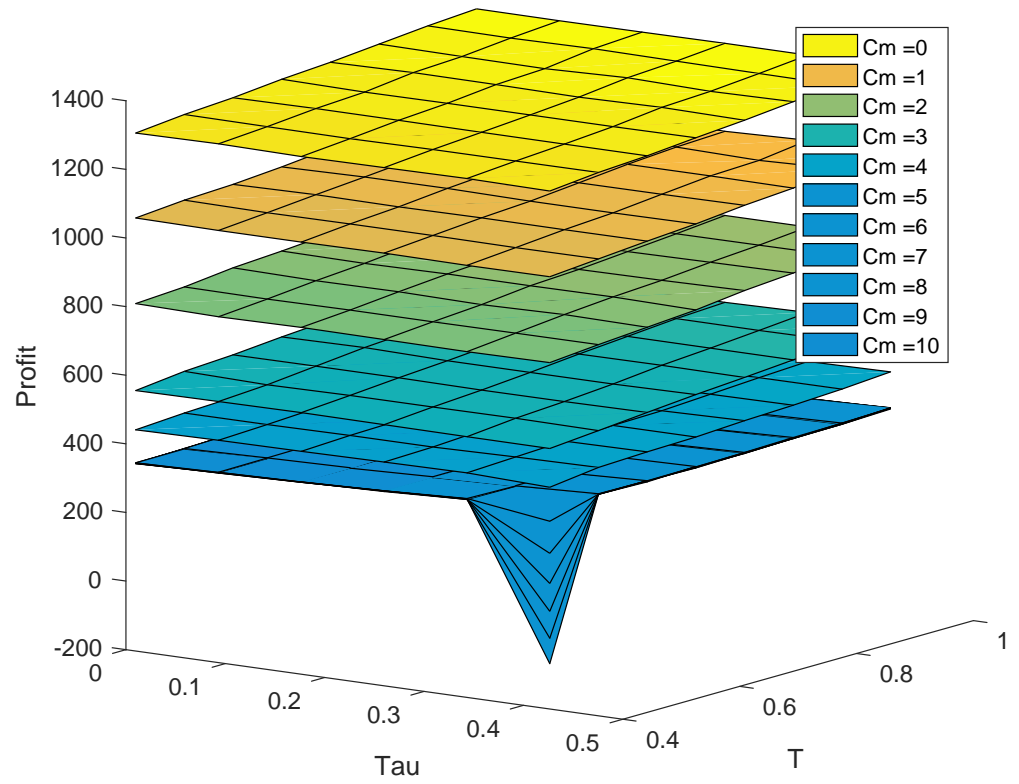

Figure 4.6: Maximum expected profit;

$$
C_{U}=5, \tau=0: \frac{5}{12}, T=\frac{5}{12}: 1
$$

Conversely, the maximum expected profit stagnates when $C_{M}=C_{U}$. As noted before, this behaviour is predicted because the retailer would instead choose the option to attain all of their goods from the local manufacturer. Once it does become profitable for the retailer to acquire a portion of their assets from the offshore manufacturer $\left(C_{M}>C_{U}\right)$, we see the maximum expected profit increase; creating a larger profit margin at each index of $C_{M}$. 


\subsection{Performance of SOMLOP Model}

\subsubsection{Observation of SOMLOP Model with Three Local Order Periods}

In this section, a more practical view of dual-source hedging will be observed. It is unlikely that a firm will only order once from an offshore source and then again once from a local source. If they are trying to observe future expected demand and hedge against it, then likely they will be able to order multiple times from their local source to do so. This section also assumes that there will be multiple selling periods (months), based on the amount of orders placed from the local source since the firm should only order more product if they have sold some inventory during the month and are expecting a higher demand before the next order period. Figure 4.7 shows the expected profit with respect to multiple local orders.

As discussed in the methodology, the firm places an order from their offshore distributor at $t=0$. As before, the firm has the option to once again order from their local source at time $t=T_{n-5}$. However, the firm can now also utilize the quick response of the local manufacturer and place more orders in $t=T_{n-4}$ and $t=T_{n-3}$, increasing the total local order periods to three. The formulated model is independent of previous order quantities, and bases the expected profit and optimal order quantities on the current inventory level and attempts to maximize future expected profit.

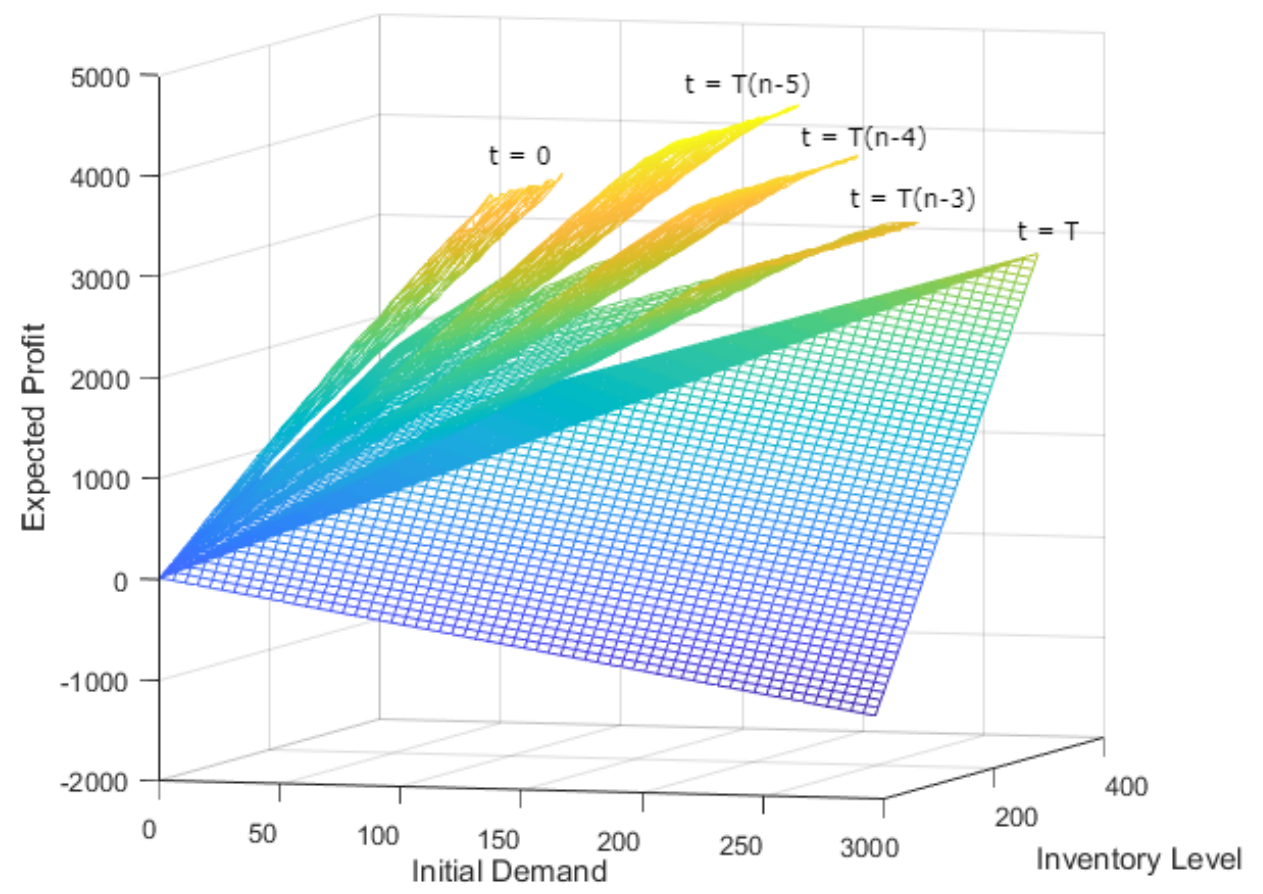

Figure 4.7: Expected Profit with Multiple Local Orders; $\mu=0.2, \sigma=0.3, T=\frac{9}{12}, T_{n-5}: T_{n-3}=\frac{5}{12}: \frac{7}{12}, C_{U}=6, C_{M}=5, P=10, P_{\text {Strat }}=4$, $P_{\text {Salv }}=3$ 
As shown in the figure, the expected profit at $t=T$ can be negative, whereas it is strictly positive in the months prior. This behaviour is intentional as the end of the final sales month is the only time where salvaging of unsold inventory occurs, and the firm can face losses depending on the consumer demand. Also noticeable is the expansion of the mesh grids as time moves forward. The model was simulated with an initial expected demand of 100 units, and the accuracy was set to capture $99.99 \%$ of the expected demand at time $t=T$. If the actual customer demand in the future months seems to be surpassing the initial estimated expected demand of 100 units, this would be captured in the model along with the following months.

\subsubsection{Local Order Quantities}

In this section, the order quantities from the local source will be observed. The results in this section consist of the same parameters used in Figure 4.7. As mentioned previously, dynamic programming is used to maximize the expected profit at each point (coordinate) in time, and the order quantities that produce the maximum expected profit are deemed the optimal order quantities.

The optimal order quantities from the local source can be seen in Figure 4.8 and Figure 4.9 when attempting to capture $99.99 \%$ of expected consumer demand. The results shown in Figure 4.8 have clear indication on whether or not is is beneficial to place an order. The result is clearly defined here because this is the final decision time $\left(t=T_{n-3}\right)$ for modifying inventory levels, and any unsold inventory has to be salvaged at a loss. Therefore, when inventory level is much higher than the initial expected demand, the firm would refrain from hedging against higher expected customer demand as it is likely that they will likely have enough inventory to meet the increase in demand. 


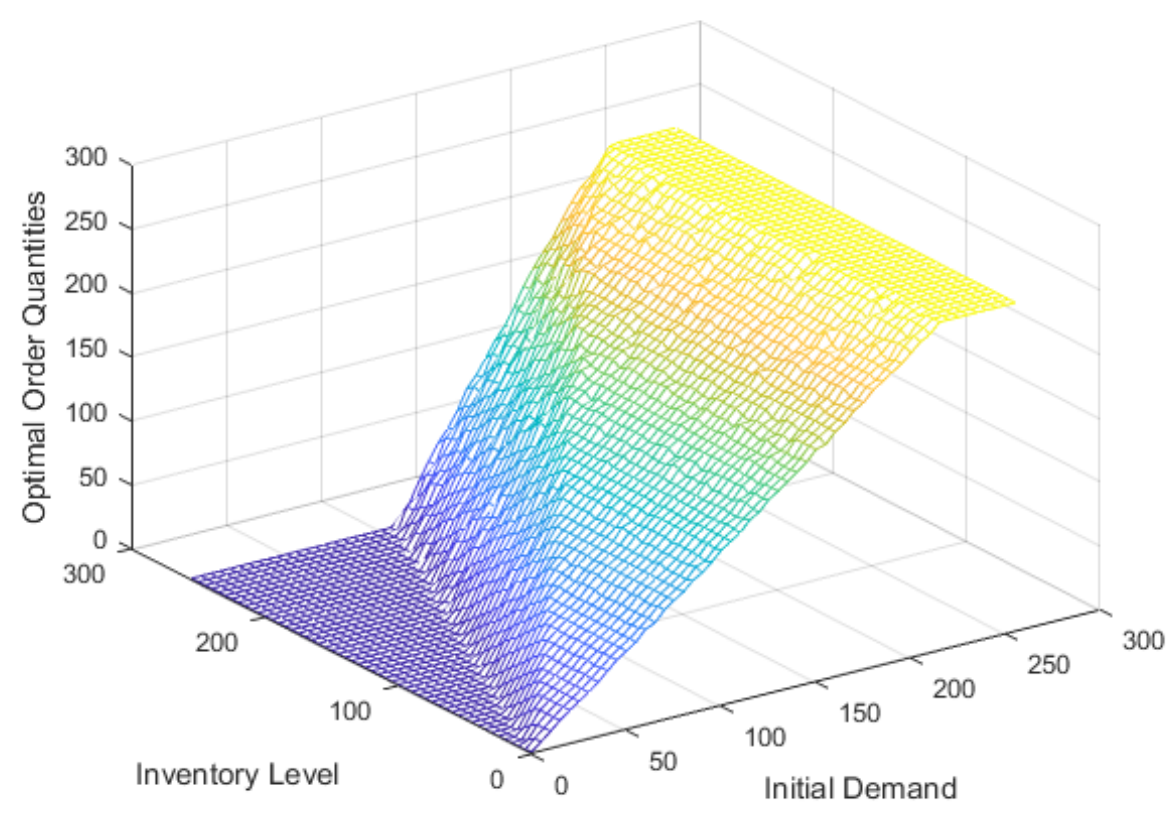

Figure 4.8: Local Purchase Quantities; $t=T_{n-3}$

When inventory levels are less than those of expected demand, the firm would place a local purchase quantity to capture additional profit in case of rising consumer demand. However, there is a point of inflection when inventory levels are equal to those of initial expected demand, and optimal order quantities tend to have a decreasing slope. The model shows that the firm should refrain from ordering excess stock and hedge against the possibility of a market downturn, where consumer demand decreases and the firm has to salvage their excess perishable inventory at a loss.

The order quantities for the last decision period are very clear, but the distinction is less obvious in the earlier months, due to the artifact of the numerical methodology - and increasing the number of simulations will increase the accuracy of the results. The plots shown in Figure 4.9 represent the optimal local order quantities for the $t=T_{n-4}$ and $t=T_{n-5}$ order periods. We can see that the optimal local order quantities follow a very similar trend to those observed in Figure 4.8, and the main contributor to the difference in order quantity $U$ for a given coordinate is the discount rate $r$ in expected profit applied across the order periods. 


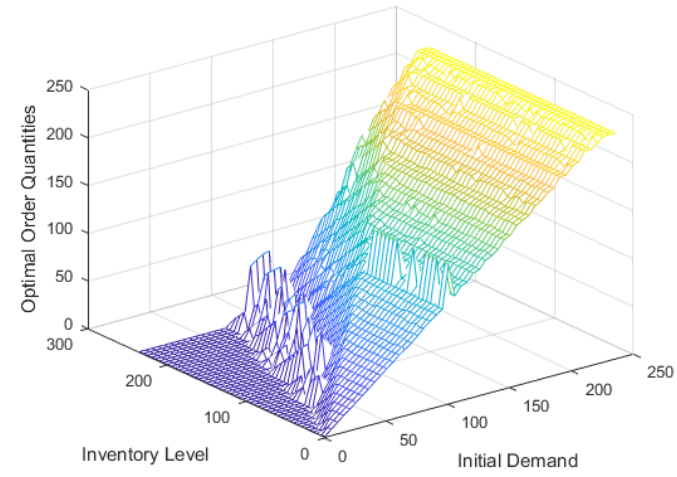

(a) Local Purchase Quantities; $t=T_{n-4}$

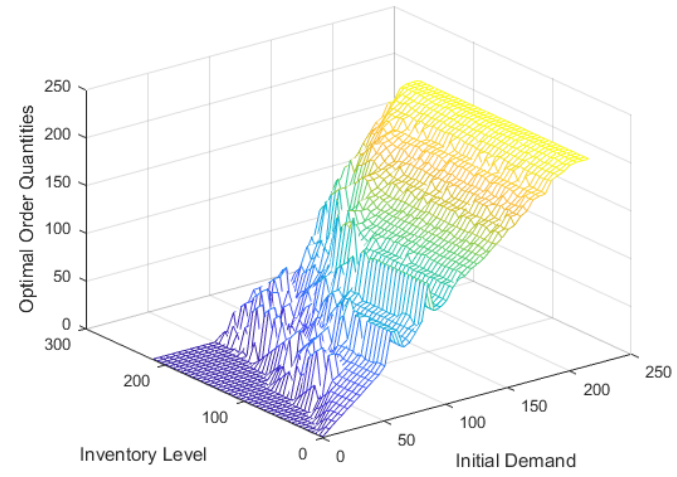

(b) Local Purchase Quantities; $t=T_{n-5}$

Figure 4.9: Optimal Local Order Quantities $(U)$

\subsection{The Value of Multiple Local Order Quantities}

In terms of offshore order quantities, Figure 4.10 shows that when multiple local order quantities are available, the firm should take a conservative approach in the amount of stock ordered from the offshore source.

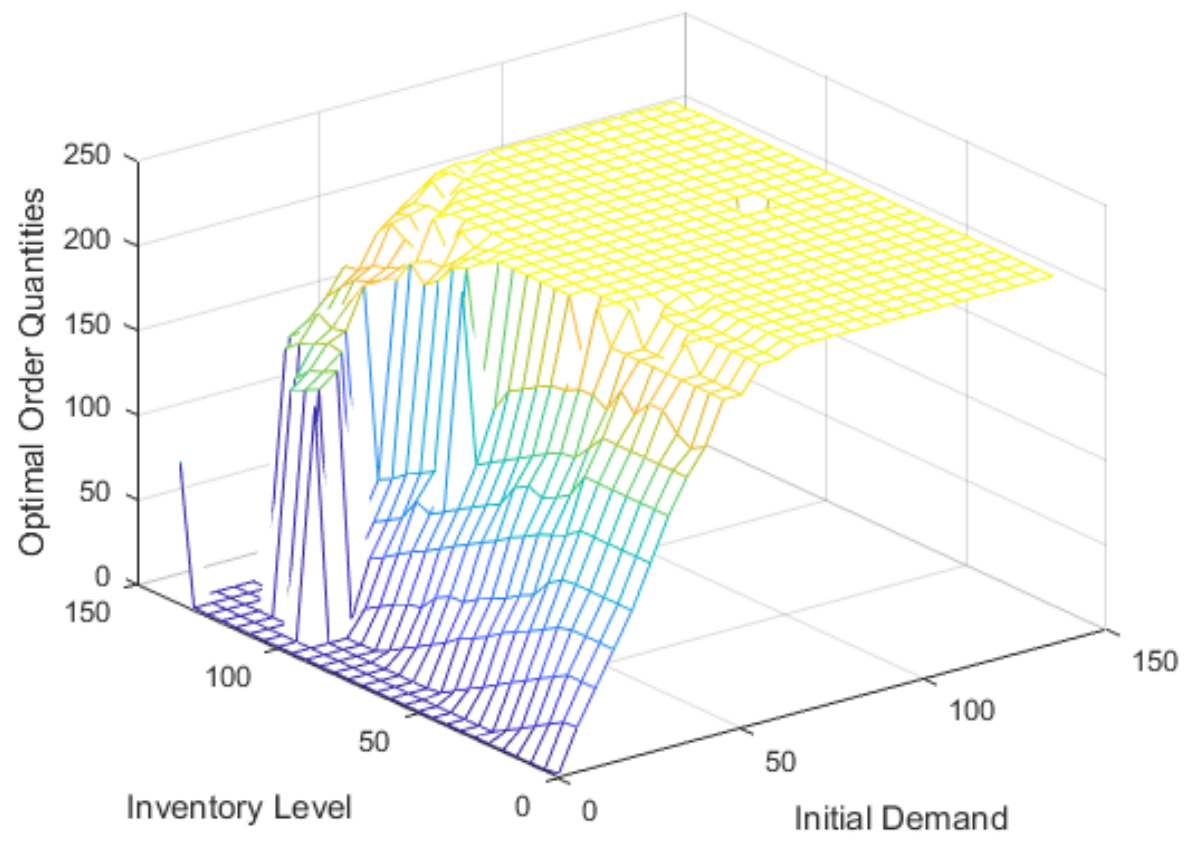

Figure 4.10: Offshore Order Quantities; $t=0$

A number of observations are evident in this figure. Initially, unless the the expected consumer demand is close to zero, the firm should make an offshore order to take advantage of 
their less expensive stock. Secondly, there seems to be a point of inflection where the increase in initial expected demand relative to the inventory level does not have an effect on the optimal offshore order quantity. The value of multiple ordering and selling periods is evident here. The underlying stochastic model shows that the expected consumer demand in the future is unlikely to decrease substantially, and the firm should take advantage of the lower cost product by buying the maximum quantity. When comparing these results to that of only a single order period from the offshore source, and no local operational hedging as shown in Figure 4.11a, the results are similar to those depicted in Figure 4.8.

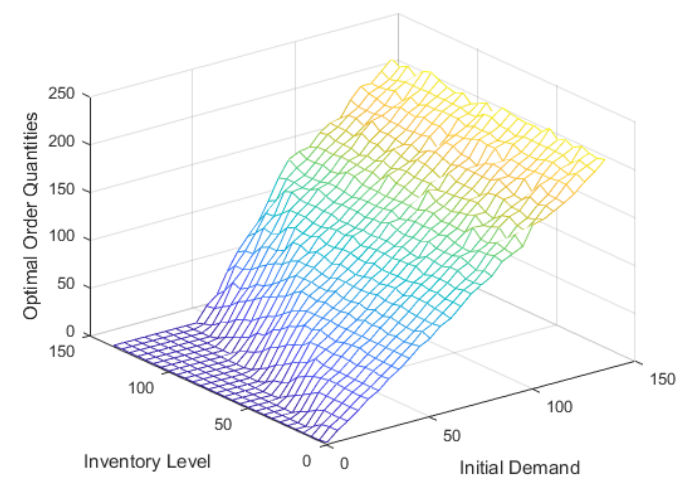

(a) Optimal Offshore Order Quantities

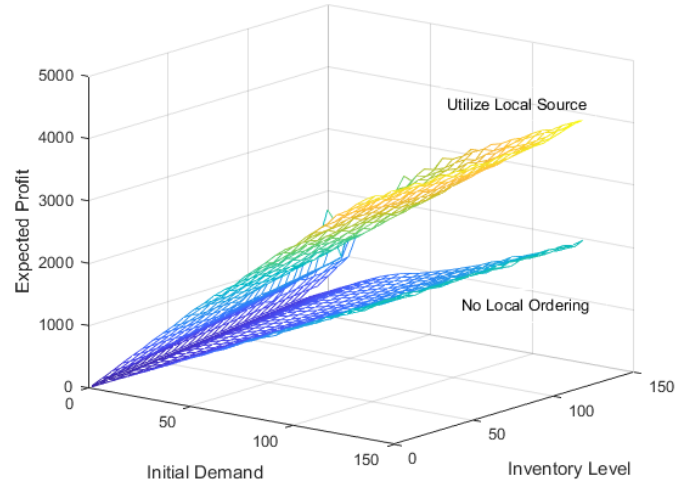

(b) Expected Profit Comparison: Offshore only vs. Dual-sourcing

Figure 4.11: Offshore Purchase Quantities and Profit - No Local Orders; $t=0$

Under the single order period (no local hedging period), the firm does not utilize the discounted prices from the offshore source nearly as much and prefers to take a conservative order approach. This is because the firm will not have the ability to operationally hedge in the future months, and only have the ability to sell their inventory at $t=T$. As a result, the expected profit of the system drops largely as shown in Figure 4.11b. A risk-averse firm, knowing that large swings in consumer demand exist, will take caution in placing large orders, when their selling period is far into the future. Like many of the results shown, the advantage of dual-sourcing is highly dependent on the input parameters $\left(P, P_{S t r a t}, P_{S a l v}, C_{U}, C_{M}\right)$ and modification of these parameters can provide results that show dual sourcing is unfavorable for profit maximization.

\subsubsection{Effect of Local Product Purchasing Cost $C_{U}$}

Local product purchasing cost can have a large influence on the expected profit of the system. Figure 4.12 presents the expected profit at $t=0$ under varying local purchasing costs $C_{U}$ and no inventory $(I=0)$ when local hedging is not utilized. As expected, since no local orders are placed, the local product purchasing $\operatorname{cost} C_{U}$ has no effect on the expected profit, and the expected profit increases with initial expected demand. 


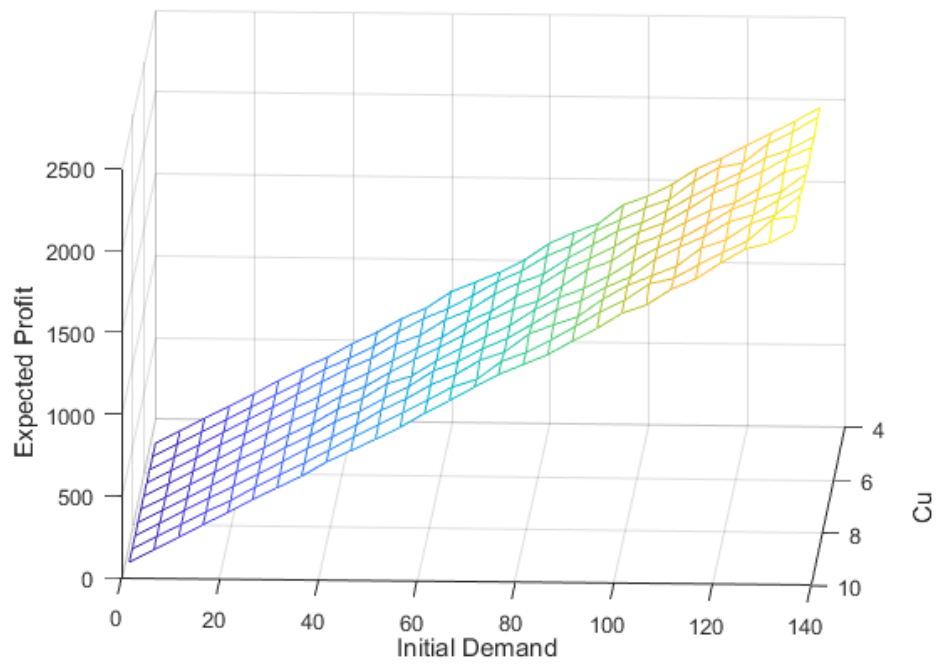

Figure 4.12: Expected Profit with Varying $C_{U}$ : No Local Order Periods;

$\mu=0.2, \sigma=0.3, T=\frac{9}{12}, C_{U}=5: 10, C_{M}=5, P=10, P_{\text {Strat }}=4, P_{\text {Salv }}=3$

When local order periods are utilized similar to those modeled in Figure 4.7 and an inventory level of zero $I=0, C_{U}$ has a large effect on periodic expected profit. Figure 4.13 shows expected profits under multiple local order periods with varying local purchasing costs such that $C_{U} \geq C_{M}$.

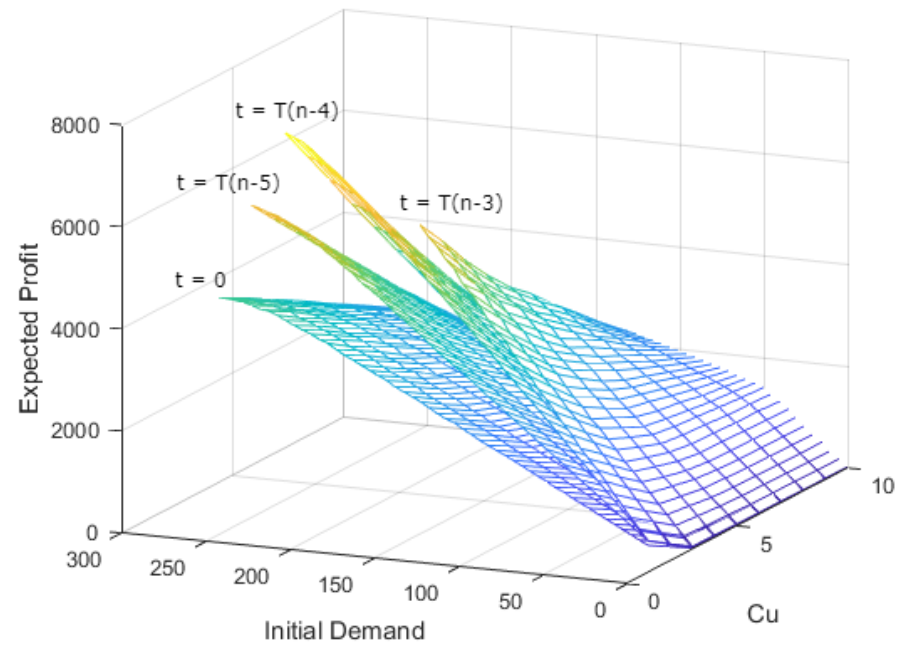

Figure 4.13: Expected Profit with Varying $C_{U}$ : 3 Local Order Periods;

$\mu=0.2, \sigma=0.3, T=\frac{9}{12}, T_{n-5}: T_{n-3}=\frac{5}{12}: \frac{7}{12}, C_{U}=1: 10, C_{M}=5, P=10, P_{\text {Strat }}=4$, $P_{\text {Salv }}=3$

As local purchasing costs increase, the expected profit in each order period under constant demand decreases and, as can be seen, the expected profits at $t=0$ are now affected by the varying local purchasing costs. However, even when $C_{U}=2 \cdot C_{M}$, the firm's expected profits 
are still greater than those to when the local supplier is not utilized. Also can be seen is the point of inflection when $C_{U} \leq C_{M}$. At this point, the firm has no benefit in offshoring as the product cost from the local supplier is equal to or less than the offshore supplier, and the firm should fully manufacture from the local source. As a result, the optimal dual-sourcing scenario is highly dependent on pricing and cost parameters $C_{U}, C_{M}, P, P_{\text {Strat }}$, and $P_{\text {Salv }}$.

\subsubsection{Minimum Order Quantities}

It is not practical that a firm has the ability to order any number of products from a supplier. Typically, industry suppliers require a minimum order quantity to fulfill the order. The flexibility of the SOMLOP model allows for modification and application of a minimum order quantity to both the offshore and local suppliers. Once again, referring to the conditions set forth for Figure 4.7, a minimum order quantity of 100 units from the offshore source and 50 units from the local source was applied and expected profit results can be seen in Figure 4.14.

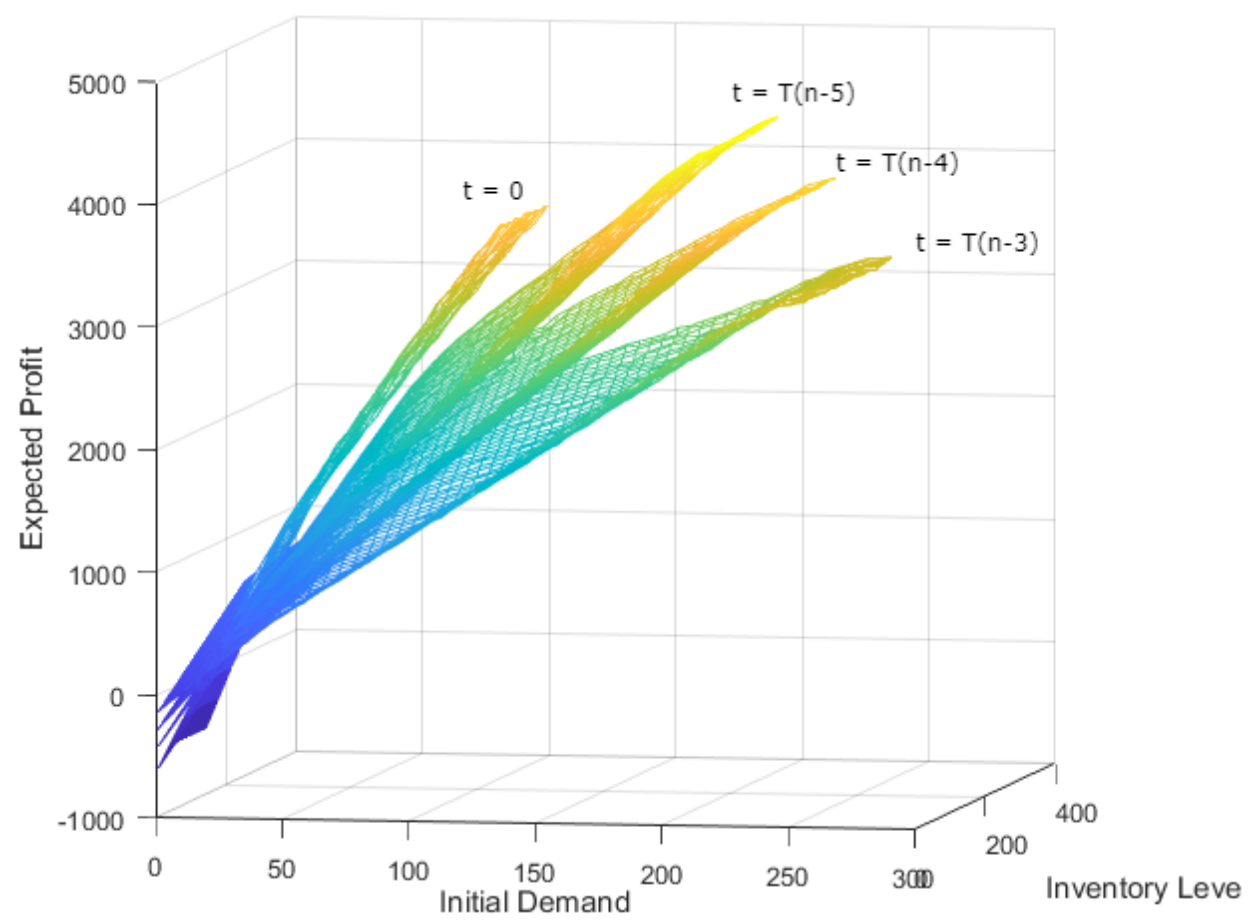

Figure 4.14: Expected Profit Under Minimum Offshore and Local Order Quantities

The expected profits at $t=T$ were not included as they are equivalent to those shown in Figure 4.7. However, now when initial expected demand is low, the firm faces negative expected profit. Under the minimum order quantity policy, the firm takes on more risk and in turn, the optimal order quantities are affected as per Figure 4.15 

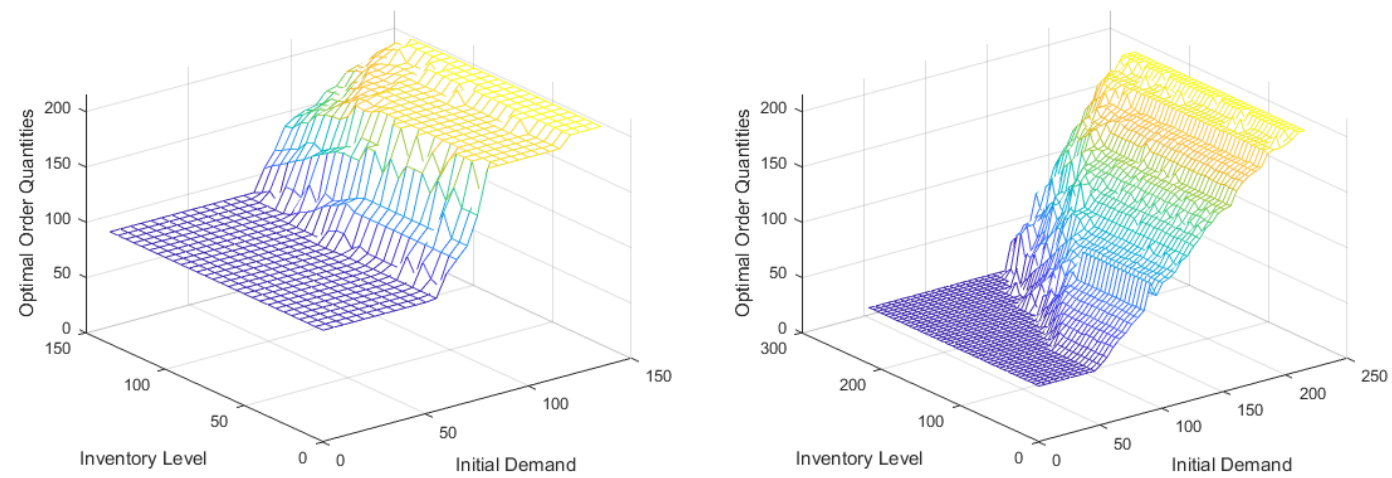

(a) Optimal Offshore Order Quantities Minimum order of 100 units

(b) Optimal Local Order Quantities October Minimum order of 50 units

Figure 4.15: Optimal Order Quantities Under Minimum Order Policy

Both the offshore and local order quantities have a similar trend when compared to the case where a minimum order quantity is not in effect as shown in Figures 4.8 and 4.10 . The minimum order quantities instead extend the "tail" end of the purchase quantities, and the firm will only order above the minimum order quantity when the initial expected demand surpasses the minimum order quantity set by the supplier. 


\section{Chapter 5}

\section{Conclusion and Future Work}

This research presented a profit maximization technique for risk-averse firms that face an uncertain future consumer demand and have the ability to operationally hedge their offshore purchases with local suppliers. Utilizing the newsvendor model and real options theories, a psuedo-analytical single offshore single local order period (SOSLOP) model was developed. Additionally, a more practical single offshore multiple local order period (SOMLOP) model was developed that can no longer be solved analytically, but provides very informative results and modifications through simple Monte-Carlo modeling processes. Finally, a method for matching distributions of expected demands based on managerial estimates was applied to the SOMLOP model to prove its effectiveness and incorporation into the industry. With these results, it has been determined that dual-sourcing provides large vaulue to firms through hedging possibilities and potentially increasing their expected profit. However, optimal order quantities from retailers and maximum period expected profits are highly affected by the pricing and cost variables set by the firm and suppliers.

Although the presented models determine optimal order quantities from each retailer depending on the current inventory status, the models do not directly track inventory levels when given a starting inventory. The models only track inventory change between order periods when the firm is deciding whether to order additional inventory from one of the sources. As a result, the model assumes that there were no selling periods between order times and inventory levels have not changed. Implementing inventory tracking from starting inventory though the end of the selling period is designated for future work.

Additionally, an implementation of a mean-reverting process to the sale price of the product based on consumer demand will be an interesting application for smaller firms that do not have unlimited inventory storage capacity or capital to purchase mass quantities from their retailers. By increasing the sale price of the product when consumer demand increases and lowering it as demand decreases and coupling this with the dual-sourcing policies mentioned in this research, can possibly provide the risk-averse firm with increased hedging. 


\section{Bibliography}

V. Agrawal and S. Seshadri. Impact of uncertainty and risk aversion on price and order quantity in the newsvendor problem. Manufacturing and Service Operationg Management, (4):410-423, 2000 .

G. Allon and J.A. Van Mieghem. Global dual sourcing: Tailor base-surge allocation to near and offshore production. Management Science, (56-1):110-124, 2010.

K.J. Arrow, T. Harris, and J. Marshak. Optimal inventory policy. Econometrica, 1951.

E.W Barankin. A delivery-lag inventory model with an emergency provision (the single-period case). Naval Research Logistics Quarterly, 8:285-311, 1961.

G.J. Burke, J.E. Carrillo, and A.J. Vakhariar. Single versus multiple supplier sourcing strategies. European Journal of Operational Research, (182):95-112, 2007.

F. Chen, A. Federgruen, and Y.-S. Zheng. Coordination mechanisms for a distribution system with one supplier and multiple retailers. Management Science, (47-5):693-708, 2001.

L. Chen, S. Li, and L. Wang. Capacity planning with financial and operational hedging in low-cost countries. Production and Operations Management, (23-9):1495-1510, 2014.

Y.F. Cheng, M. Xu, and Z.G. Zhang. A risk-averse newsvendor model under the cvar criterion. Operations Research, (57-4):1040-1044, 2009.

J. Chod, N. Rudi, and J.A. Van Mieghem. Operational flexibility and financial hedging: Complements or substitutes. Management Science, (56-6):1030-1045, 2010.

Y. Chou, C.-T. Cheng, F.-C. Yang, and Y.-Y. Liang. Evaluating alternative capacity strategies in semiconductor manufacturing under uncertain demand and price scenarios. Int. J. Production Economics, (105):591-606, 2007.

A. K. Dixit and R. S. Pindyck. Investment Under Uncertainty. Princeton University Press, Princeton, N.J., 1994.

H. Fu, B. Dan, and X. Sun. Joint optimal pricing and ordering decisions for seasonal products with weather-sensitive demand. Discrete Dynamics in Nature and Society, pages 1-8, 2014. 
Y Fukuda. Optimal policies for the inventory problem with negotiable leadtime. Management Science, 10:690-708, 1964.

V. Gaur and S. Seshadri. Hedging inventory risk through market instruments. Manufacturing and Service Operations Management, (7-2):103-120, 2005.

J. Gotoh and Y. Takano. Newsvendor solutions via conditional value-at-risk minimization. European Journal of Operational Research, (179):80-96, 2007.

Y. He, S.-Y. Wang, and K.K. Lai. An optimal production-inventory model for deteriorating items with multiple-market demand. European Journal of Operational Research, (203):593600,2010 .

W. Ho, T. Zheng, H. Yildiz, and S. Talluric. Supply chain risk management: a literature review. International Journal of Production Research, 53(16):5031-5069, 2015.

J. Hou, A.Z. Zeng, and L. Sun. Backup sourcing with capacity reservation under uncertain disruption risk and minimum order quantity. Computers and Industrial Engineering, (103): 216-226, 2017.

S. Jaimungal and Y. Lawryshyn. Using managerial revenue and cost estimates to value early stage real option investments. Annals of Operations Research, pages 1-18, 2016.

J. Jia and Q. Hub. Dynamic ordering and pricing for a perishable goods supply chain. Computers and Industrial Engineering, (60):302-309, 2011.

B. Keren. The single-period inventory problem: Extension to random yield from the perspective of the supply chain. Omega, (37):801-810, 2009.

P. Kouvelis, R. Li, and Q. Ding. Managing storable commodity risks: The role of inventory and financial hedge. Manufacturing and Service Operations Management, (15-3):507-521, 2014.

S. Li and L. Wang. Outsourcing and capacity planning in an uncertain global environment. European Journal of Operational Research, (207):131-141, 2010.

S Minner. Multiple-supplier inventory models in supply chain management: a review. International Journal of Production Economics, 81-82:265-279, 2003.

H.K. Okyay, F. Karaesmen, and S. Ozekici. Hedging demand and supply risks in the newsvendor model. OR Spectrum, (37):475-501, 2014.

J.H. Park, B. Kazaz, and S. Webster. Risk mitigation of production hedging. Production and Operations Management, (26-7):1299-1314, 2017.

M. Parlar and D. Perry. Inventory models of future supply uncertainty with single and multiple suppliers. Naval Research Logistics, 43(191-210), 1996. 
M. Rabbani, N.P. Zia, and H. Rafiei. Joint optimal dynamic pricing and replenishment policies for items with simultaneous quality and physical quantity deterioration. Applied Mathematics and Computation, (287-288):149-160, 2016.

L. Shu, F. Wu, J. Ni, and L.K. Chu. On the risk-averse procurement strategy under unreliable supply. Computers and Industrial Engineering, (84):113-121, 2015.

S. Spinler and A. Huchzermeier. The valuation of options on capacity with cost and demand uncertainty. European Journal of Operational Research, (171):915-934, 2006.

C.S. Tang. Perspectives in supply chain risk management. Int. J. Production Economics, (103): 451-488, 2006.

L. Trigeorgis. Real Options: Managerial Flexibility and Strategy in Resource Allocation. MIT Press, Cambridge, Mass., 1996.

S. Uryasev and R.T. Rockafellar. Optimization of conditional value-at-risk. The Journal of Risk, (2-3):21, 2000.

H. Wang, B. Chen, and H. Yan. Optimal inventory decisions in a multiperiod newsvendor problem with partially observed markovian supply capacities. European Journal of Operational Research, (202):502-517, 2010.

A.S. Whittemore and S.C Saunders. Optimal inventory under stochastic demand with two supply options. SIAM Journal on Applied Mathematics, 32:293-305, 1977.

A. Xanthopoulos, D. Vlachos, and E. Iakovou. Optimal newsvendor policies for dual-sourcing supply chains: A disruption risk management framework. Computers and Operations Research, (39):350-357, apr 2011.

L. Zhao and A. Huchzermeier. Integrated operational and financial hedging with capacity reshoring. European Journal of Operational Research, (260):557-570, 2017. 